\title{
Overlapping Consensus, Public Reason, and the Possibility
} of Exclusion

\author{
by \\ Peter Ferri
}

A thesis submitted to the Faculty of Graduate and Postdoctoral Affairs in partial fulfillment of the requirements for the degree of

Master of Arts

in

Philosophy

Carleton University

Ottawa, Ontario

\author{
(C)2016 \\ Peter Ferri
}




\begin{abstract}
John Rawls's idea of an overlapping consensus, and his corresponding ideal of public reason, lay the ground work for the modern debate on political identity and stability in democratic states. Many authors over the years have critiqued Rawls for being exclusionary in some sense. I argue that Rawls is capable of responding to many of these critiques, but ultimately, his ideal of public reason as a rigid method for creating lasting social unity is too problematic to be effective. Rawls's idea of an overlapping consensus must be divorced from his account of public reason. Using the work of Charles Taylor and Jocelyn Maclure on secularism, I contend that the best way to achieve a lasting overlapping consensus is through the fostering of a public moral psychology that strives to find political identity within the existing pluralism rather than in spite of it.
\end{abstract}




\section{Table of Contents}

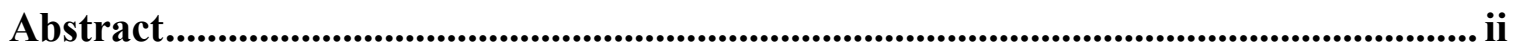

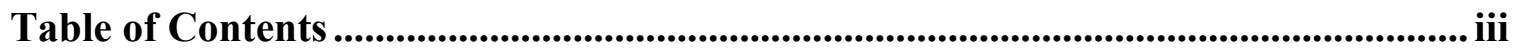

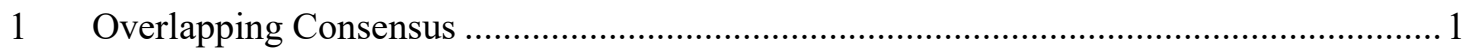

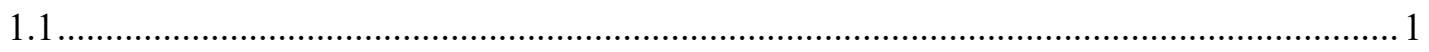

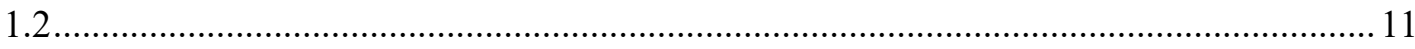

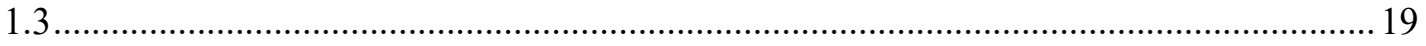

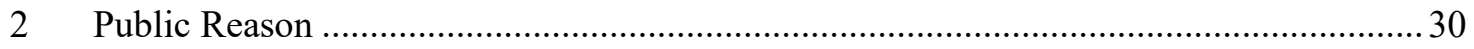

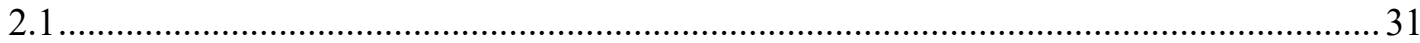

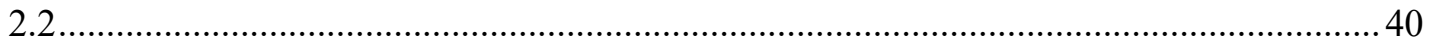

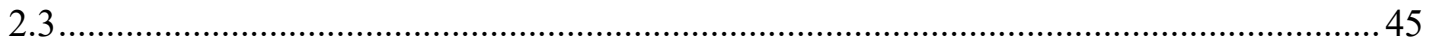

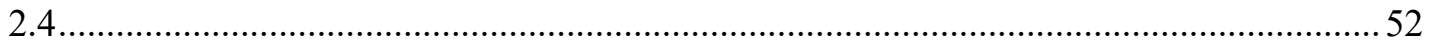

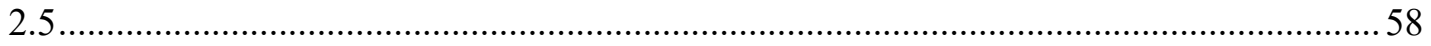

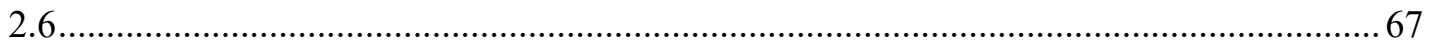

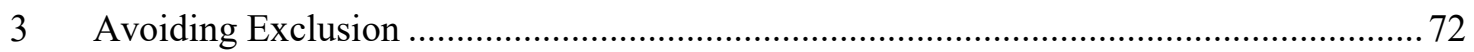

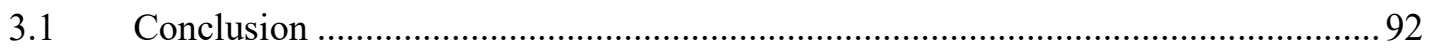

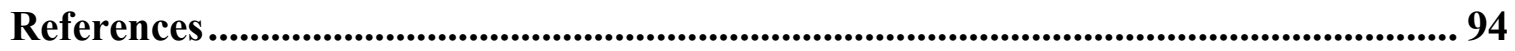




\section{Overlapping Consensus}

John Rawls's idea of an overlapping consensus provides a model for how all individual citizens in a liberal society can maintain moral allegiance to the state, despite these individuals holding a wide variety of potentially incompatible personal beliefs. The main idea is that citizens will agree on political values that can be supported by a wide variety of moral doctrines. Many critics of Rawls's approach claim that this model is exclusionary for one reason or another. The varied critiques all seem to argue that the holders of certain belief systems or minority groups in society will not be capable of participating as equal members of society. In this thesis I will explore these critiques and evaluate whether or not overlapping consensus is a useful model for creating this kind of moral allegiance. I will begin by surveying Rawls's overlapping consensus. This chapter will then address critiques aimed at Rawls while beginning to compare Rawls's account of an overlapping consensus to the work of Charles Taylor on secularism. The next chapter seeks to separate overlapping consensus from the idea of public reason to show that any claims of exclusion lie with taking Rawls's public reason as a strict rule. Lastly, I use Taylor's account of secularism and the overlapping consensus to show that the best way to create moral allegiance to the state is through a commitment to the fostering of a moral psychology that values mutual understanding.

\section{1}

Rawls is applying his ideas to a liberal constitutional democracy. To Rawls this indicates that citizens have enough freedom and equality to formulate and then pursue their own conceptions of the good life. Put in another way, the state cannot tell you what to value. 
That being said, Rawls also argues that it is the job of liberal societies to perpetuate that liberalism. The problem of how to do this comes from the fact of pluralism. As long as individuals have the ability to conceive of and then pursue their conception of the good, in line with any moral doctrine, then in a liberal society conflicting viewpoints will emerge. It is the job of political liberalism to allow for this freedom to create a plurality of views, while also fostering moral allegiance to the state. While discussing constitutional democracies, which for Rawls are liberal societies, he states that "one of its most important aims is presenting a political conception of justice that can not only provide a shared public basis for the justification of political and social institutions but also helps ensure stability from one generation to the next."1 This means that it will be a society which values giving people freedom, over choosing a good life while maintaining the allegiance of these people.

Liberalism accomplishes this allegiance by starting with a division between people's personal lives and the values they hold there, and the political realm of the state. Individuals will form a political conception of justice, which means a sense of justice that only applies to the basic structure of society. ${ }^{2}$ Comprehensive doctrines are those moral doctrines which apply to all aspects of life, hence the term 'comprehensive'. The goal of an overlapping consensus is to create a basic idea of justice in the liberal society that inspires moral allegiance from citizens, without conflicting with any comprehensive doctrine in that society. For example, two individuals may exist harmoniously in society despite one being comprehensively utilitarian, and one being comprehensively Christian. 1(1987): 1.

1. John Rawls, "The Idea of Overlapping Consensus," Oxford Journal of Legal Studies 7, no.

2. Ibid., 4. 
Throughout their daily lives, these citizens will often make different moral choices, such as choosing to volunteer at a homeless shelter when given the opportunity. They could also potentially have different conceptions of the good. A Christian person might spend their life being as pious as possible in preparation for their death, whereas a utilitarian person may spend their life maximizing utility in all aspects of their life. What matters is that they have a shared commitment to freedom and equality, within their political conceptions of justice, which allows liberal society to exist. Their conception of the good need not necessarily be determined by their comprehensive doctrine, but understanding how an individual's comprehensive doctrines and conceptions of the good interact with their political conception of justice is paramount.

An overlapping consensus on the basic structure of society needs to be capable of being justified by all major comprehensive doctrines in society, but should only be discussed in terms of political conceptions of justice. During public debate, Rawls argues we should strive for neutrality. If an overlapping consensus comes about as he expects, then the various groups in society which hold conflicting views will, over time, take in the values of liberalism because those values allow citizens to cooperate. The kind of consensus Rawls is looking for is a practical one. Political conceptions of justice will be moral insofar as they are normative ideals, but an overlapping consensus is not meant to move us towards any conception of true morality in the world. Rather, Rawls tells us that an overlapping consensus emerges from the practical concern of everyone trying to work together. Modern democracies emerged from wars over religious and other comprehensive doctrines. Societies tried to ground justice in specific comprehensive doctrines, but this can never lead to all citizens having allegiance to a state unless the 
state falls into tyranny, and this ultimately leads to more conflict. ${ }^{3}$ The goal of justice as fairness, Rawls's overarching goal for a liberal democracy, is to create a practical conception of justice, and Rawls says that "it presents itself not as a conception of justice that is true, but one that can serve as a basis of informed and willing political agreement between citizens viewed as free and equal persons." ${ }^{\text {R }}$ Rawls says that if we just look at modern democracies, we can see that the differences in comprehensive doctrines are too great for us ever to find a single one on which society can successfully base justice. In our politics, we must leave behind the religious and philosophical questions that divide us. Metaphysical and epistemological concerns have no place in the political realm, and there is no problem with having a conception of the political person. This means that "the conception of citizens as free and equal persons, need not involve, so I believe, questions of philosophical psychology or a metaphysical doctrine of the nature of the self." goes on to say that, "by this method of avoidance, as we might call it, existing differences between contending political views can at least be moderated, even if not entirely removed, so that social cooperation on the basis of mutual respect can be maintained."6 Functioning in the political realm requires no prior commitments to comprehensive doctrines. Respecting each other as free and equal is conducive to reaching agreement, which is useful for all members of society. A political conception of justice is where consensus that allows for widespread moral allegiance will form. Citizens will still be able to decide for themselves what is morally right, as well as what they wish to pursue in

3. Rawls, "Overlapping Consensus," 4.

4. John Rawls, "Justice as Fairness: Political not Metaphysical," Philosophy \& Public Affairs 14, no. 3 (1985): 230 .

5. Ibid., 230-231

6. Ibid., 231. 
their lives, but the basic political values of justice will be shared when individuals operate as a political citizen.

Despite his emphasis on historical events like the Reformation leading to insurmountable differences in comprehensive doctrines, Rawls does see his overlapping consensus as part of a historical narrative that begins from some consensus. ${ }^{7}$ Rawls's overlapping consensus cannot create unity from completely dissenting views. He claims that no agreement can come from these situations. In order even to begin a fruitful debate, the participants must begin with some shared premises. Rawls states: "Justification in matters of political justice is addressed to others who disagree with us, and therefore it proceeds from some consensus: from premises that we and others recognize as true, or as reasonable for the purpose of reaching a working agreement on the fundamentals of political justice." ${ }^{\prime 8}$ A society will, in due course, begin to share some form of consensus on certain values when they are ready to enter into a constitutional arrangement that allows for cooperation as political persons, which will occur when they are ready to view others as free and equal individuals worthy of respect. The debate on political conceptions of justice can only begin if every party is capable of seeing other viewpoints as having valid justifications based on shared political values. This beginning consensus happens slowly, but will take hold in the minds of individuals. Soon members of the society with varying comprehensive doctrines will all have similar intuitions about justice. Rawls says that they will have "certain fundamental intuitive ideas viewed as latent in the public political culture of a democratic society." 9 An overlapping consensus

7. Rawls, "Overlapping Consensus," 6.

8. Ibid., 6.

9. Ibid., 6. 
will emerge from this over time, but only if we have a political realm cut off from private concerns. If we return to our Utilitarian and Christian citizens, we can perhaps imagine how they will not reach agreement if both adamantly argue for a constitution grounded in the principles of their comprehensive doctrines. Living together will eventually allow these individuals to begin to see each other as having valid ideas about purely political conceptions of justice. They will begin to see, perhaps, that both groups value their ability to speak freely about their beliefs, and this will leads to a common decision on a right to free speech. Political principles will be formed from consensus that is born from these ideas which everyone has come to value in some sense simply because of constant interaction causing an eventual sharing of intuited values. An overlapping consensus can emerge from consensus born of intuitions developed as they live and work together, so long as the participants in the political project do not try to justify those intuitions in terms of their comprehensive doctrines.

It is important to note that Rawls does think that the principles of justice can be debated past their inception, but they must only be debated in terms upon which everyone can agree. Justice is about forming the basic structures and institutions of society, and this process is to be controlled by public reason. Basically, public reason must only rely on information available to everyone. The boundaries of public reason are set when Rawls says that there is "no better practicable alternative than to limit ourselves to the shared methods of, and the public knowledge available to, common sense, and the procedures and conclusions of science when these are not controversial." ${ }^{10}$ Any forms of justification that go outside of this would rely on comprehensive doctrines, or at least personal

10. Rawls, "Overlapping Consensus," 8. 
experiences that go beyond the political. In his later works, Rawls refines this idea of public reason, and adds an important proviso to public reason that allows for mentioning justifications that stem from comprehensive doctrines, so long as individuals also present reasons capable of being accepted by anyone. Public reason will be discussed at length in the next chapter, but for now it is important to understand the connection to Rawls's overlapping consensus. The consensus is built around citizens interacting publicly as political persons when debating the basic structure. To accomplish this, Rawls believes they must debate using neutral terms that any free and equal individual can see as rational in some sense, or else society will fall into conflict when one group tries to impose their comprehensively moral ideals on the basic structure of the state. Before the formulation of his proviso, Rawls does allow for other instances in which individuals can bring their comprehensive beliefs into the political realm. We can bring our comprehensive doctrines into public reason "whenever someone insists, for example, that certain questions are so fundamental that to ensure their being rightly settled justifies civil strife." ${ }^{11}$ The proviso would seem to render this moot, unless Rawls is claiming that in certain situations it is reasonable to use comprehensive doctrines as justifications. In that case, it is interesting that Rawls believes this necessarily causes civil strife. Rawls thinks that the civil strife that necessarily emerges from groups arguing over comprehensive doctrines leads to a valuing of cooperation. It is, however, simply valuing cooperation as a means to avoid something worse. An overlapping consensus must get beyond this. It must not be a way to avoid something worse, but rather it must create a way for all groups in society to share values in earnest.

11. Rawls, "Overlapping Consensus," 14. 
Rawls's overlapping consensus becomes a way to regulate and ensure agreement over time. It is simply a fact that people will have different comprehensive doctrines, and the only way to truly eliminate this fact of pluralism is through force. ${ }^{12}$ Liberalism, though, respects people's ability to choose various forms of the good life, and so it cannot simply stamp out pluralism. Rawls is not trying to eliminate debate. Ongoing debate in the political realm is best for society. Nevertheless, Rawls does set up the relationship to pluralism in the private part of life as having the potential to become antagonistic to the ends of the state. A liberal society is concerned in some sense with perpetuating itself, as we discussed. In some instances then, an allegiance to the shared political conceptions of justice must come before commitments to comprehensive doctrines, or to a conception of the good. If citizens do not eventually come to value justice as set out by the overlapping consensus more than their private views, (which include comprehensive doctrines and a conception of the good), then the citizens of that state have not moved past agreement based solely on mutual benefit. Recognizing this mutual benefit and seeing the overlapping consensus as practical in this way, is a very important for people in moving towards the overlapping consensus. Citizens must then move past that conception of the overlapping consensus though, since valuing the political conception of justice that informs the basic structure of society for itself is important to ensure those values continue from one generation to another.

Rawls insists that his overlapping consensus goes beyond a mere modus vivendi, which is an agreement between the groups made simply for mutual benefit. An important reason for this is the moral force that he sees this conception of justice as having. The

12. Rawls, "Overlapping Consensus," 10. 
moral allegiance it engenders is something that the groups in society will believe, independently of their comprehensive doctrines. Rawls asks us to imagine three groups in society. There is a group of people with religious views, a group with Kantian or Utilitarian liberal views, and lastly, a group of people who affirm the political conception of justice with no comprehensive doctrine outside of those views. ${ }^{13}$ In a society that has achieved the overlapping consensus, these three groups will disagree on many courses of action in every aspect of life except the political. Rawls argues that they will maintain their comprehensive doctrines, but internalize and intrinsically value the political conception of justice, because it has undeniable benefits. Yet, they are not agreeing to it simply for their own benefit. The overlapping consensus will make it so that every comprehensive doctrine is in agreement with justice and owes it moral allegiance. This will lead to stability which a modus vivendi cannot achieve. ${ }^{14}$ If the groups in society agreed to the principles of justice purely for their own benefit, then justice would change whenever one group became more dominant. ${ }^{15}$ The moral allegiance of a true overlapping consensus avoids this problem. There is stability because everyone in society formed and debated these principles of justice from their own intuitive values that arose independently of their comprehensive doctrines. Originally, though, Rawls says that constitutional democracies may be born from a modus vivendi. ${ }^{16}$ This is how citizens will begin to see that value of cooperation, and then they will develop conceptions of justice to which they are all capable of having moral allegiance to in some sense. The conceptions of justice themselves may initially be a modus vivendi, but Rawls believes

13. Rawls, "Overlapping Consensus," 9.

14. Ibid., 11.

15. Ibid.

16. Ibid., 19. 
that among the major groups of comprehensive doctrines, each generation will internalize the political values and make them a part of their own doctrines. ${ }^{17}$ It is in this sense that people move from shared intuitions and practical agreement, to actually holding the values of the state's basic structure as a constituent aspect of their own beliefs. Consensus must come from consensus, but every society begins by dealing with the fact of pluralism. There need to be shared premises for Rawls or else there can be no useful discussion. Overlapping consensus is the method by which stability is achieved despite pluralism. The consensus comes from defining the terms that allow for cooperation in the state, but then becomes the shared values and basis for agreement to which everyone can make reference to in public debate. They become values endorsed for their own merit.

In Rawls's view, the reasonable person will have no reason to go against the social cooperation that comes from this historical process. Once we have the conceptions of justice, regulated by public reason, the reasonable person will value social unity too greatly to go against it. This will be a major cause for internalizing and valuing the conception of justice, explained as such:

The virtues of political cooperation that make a constitutional regime possible are, then, very great virtues. I mean, for example, the virtues of tolerance and being ready to meet others halfway, and the virtue of reasonableness and the sense of fairness. When these virtues (together with the modes of thought and sentiments they involve) are widespread in society and sustain its political conception of justice, they constitute a very great public good, part of society's political capital. Thus, the values that conflict with the political conception of justice and its sustaining virtues may be normally outweighed because they come into conflict with the very conditions that make fair social cooperation possible on a footing of mutual respect. ${ }^{18}$

When people are already valuing tolerance, reasonableness, and a sense of fairness, then they will be unlikely to break the social cooperation they achieve. Comprehensive

17. Rawls, "Overlapping Consensus," 19.

18. Ibid., 17. 
doctrines are not static, or even uniform among the various groups of believers and followers. Neither does a comprehensive doctrine have to be a moral doctrine set up as part of a group ideology. Ideally, for Rawls, these virtues of the political values of the state will entice later generations to enact their comprehensive doctrines in terms that are more in line with these political values. People will not only internalize the conception of justice in terms of relating it to their comprehensive doctrine, but will conceive of things differently through the appropriate "modes of thought and sentiments."19 An overlapping consensus helps us appreciate the values that let us live with pluralism. It does not help us to realize other comprehensive doctrines as reasonable in their own right, but it does allow for political agreement, and the values that make this agreement possible commit us to tolerating pluralism.

\section{2}

An overlapping consensus makes a fair amount of sense and is very useful for seeing how we can form a political identity in the context of a state that encourages pluralism. We can also begin to see the potential for political exclusion and alienation that we need to be concerned with if we value freedom to choose our personal values. In Rawls's historical narrative, people begin with great differences in their comprehensive doctrines and move towards consensus before they can reach an overlapping consensus. Yet, I contend that justice precedes people's choices of the good life. This is because Rawls wants us to formulate justice in terms that are outside our comprehensive doctrines, and then to internalize the conceptions of justice within our own comprehensive doctrine.

19. Rawls, "Overlapping Consensus," 17. 
Effectively, justice is prior to our choices of the good life, because, in order to make decisions about justice, we must abstract ourselves from our comprehensive doctrines. People can only choose the good lives that are in line with justice. On one hand this makes sense. We do not allow serial killers to follow their choice of the good life and murder indiscriminately. At the same time, it seems to be a limiting factor on freedom if people are only able to develop and choose their version of the good in line with certain principles. For Rawls, this is not an issue. People need to know what they can legitimately take from the state, and what their roles as citizens are before choosing how they should live their lives. We can, however, ask if these choices are truly appropriate in every situation, and if they allow people to make the choices to which they should be entitled.

Consider the case of immigrants to a society. Rawls argues that "an overlapping consensus exists in a society when the political conception of justice that regulates its basic institutions is endorsed by each of the main religious, philosophical, and moral doctrines likely to endure in that society from one generation to the next. ${ }^{, 20}$ This means that not every cultural group needs to be part of the consensus in society in order for there to be an overlapping consensus. It would seem that, if a small cultural group immigrates to the society that has achieved an overlapping consensus, then it could face difficulties in participating politically. If the views of minority cultural group are not in line with the political conception of justice in society, and said group lacks the same initial intuitive values, then it will lack the ability to adequately participate in public reason. Rawls would say, I argue, that allowing such a minority group to participate in public reason, 
using their comprehensive doctrines alone as the basis of justification, will just derail any debate, because the group is incapable of starting with some shared premises. It is fine to look at the overlapping consensus as an evolution over time involving fixed and stable groups within that society that do survive over generations, but if you consider the case of minority groups that come into the state after overlapping consensus has occurred, it seems difficult to allow them space in the political debate until they have sufficiently assimilated the political values of the state independently of the values their group has brought into the state. Yet, according to Rawls, this seems to take generations, and if the group is small enough and is not likely to last for generations in the society, Rawls seems unconcerned with them. Such an immigrant group would potentially continue to live in such a state because of the security it provides. This leads to another situation of modus vivendi, only instead of it being a shared condition by the various members of society, one group is being politically alienated while the more dominant groups can continue to participate actively. If an overlapping consensus sets up the shared values that are appropriate for making justifications in political debates, then not having a belief in those justifications allows the other groups to dismiss your justifications as simply inappropriate or not worthwhile.

The idea that groups which are unlikely to persist in the society over time do not need their cultural freedom protected is perhaps an extreme way of looking at this issue. To give Rawls the benefit of the doubt, I feel certain he would say that even smaller groups would eventually see the value of social cooperation and internalize the political principles of justice. Again, though, this could potentially take generations. Then even if the group does eventually achieve political participation, if we value cultural freedom we 
would want access to the political debate not to be entirely dependent on someone's cultural background. The political debate should be open to all regardless of the status of their comprehensive doctrine's relationship with the political conception of justice, because of the very democratic values of tolerance and fairness suggested by Rawls.

An example of this that goes beyond immigration would be the Indigenous population of Canada. This population was essentially conquered by a force that at the time was governed by comprehensive doctrines. As the political landscape slowly changed over hundreds of years, and various groups in society, such as the French Catholics and the English Protestants, began to move towards a kind of consensus on basic principles, the Indigenous population continued to resist the dominant views, and strive for a preservation of their type of self-rule. After years of the Canadian state attempting integration of the Indigenous population through, essentially, a cultural genocide, some in the Indigenous population reject the authority of the Canadian state and refuse to participate politically according to the terms set out by that state. Consider also the far-right in the United States of America who still reject the authority of the federal government. How can these populations be expected to participate effectively in politics when they are alienated from the terms and values that supposedly allow for productive discussion in the public sphere? If not all groups have become part of the overlapping consensus in that society, then is there no consensus? Or do we simply have groups of unreasonable people with unreasonable comprehensive doctrines? Rawls does discuss unreasonable doctrines in the context of public reason, but leaves their identification, and how to handle them, up to individual societies. Nonetheless I find it hard to claim that the situation in all of the above examples is entirely unreasonable. 
Perhaps this is too extreme a take on Rawls. We must look at how permeable Rawls believes the public and private realms to be. We have seen that he does allow some overlap, in that you can at least nominally state which comprehensive doctrine motivates your participation in the public realm; it would seem that Rawls would not go so far, for example, as to ban the wearing of religious symbols in public areas such as schools. Still, the language he uses to set out the boundaries of public reason appears to be more exclusive than is necessary for his ends, and also seems unfeasible. There are some issues of great importance to society that cannot be agreed upon solely through terms that everyone can accept. A Christian may accept the political conception of justice developed in that society because it fits into their world view and can be supported by the teachings of Christ. If the issue of abortion becomes a topic of public debate, and part of the political conception of justice involves holding personal autonomy above other considerations, then there is potentially a conflict between the Christian's political beliefs and comprehensive doctrine. What is at conflict is a belief in what constitutes life, and whether or not someone's autonomy should be protected over another's life. The Rawlsian response would be that even if the Christian does not think that the value of autonomy outweighs the value of the potential for human life, the Christian will, at minimum, recognize autonomy as an important value and, if abortion is legalized in that state, respect the conclusion that the society has reached. How satisfying this response seems to us will come down to the debate in question. Much of the public debate on abortion revolves around what constitutes life. Finding a scientific definition that all reasonable people can accept, as Rawls would want us to do given his outline of public reason, is difficult if not impossible given how that immediately contradicts the deeply 
held beliefs of many Christians. In such a circumstance the comprehensive beliefs of the Christian are his only source of justification for why he rejects any scientific finding. It would then seem that finding common grounds for determining what can be agreed upon by everyone is not simple or unchanging.

Michael Barnhart argues that Rawls's overlapping consensus does not succeed in bringing about agreement from many different comprehensive doctrines. Rather, he argues that Rawls has outlined the system by which the varying comprehensive doctrines in a society become comprehensively liberal. Rawls, for Barnhart, is beginning with liberalism. For Barnhart, the only way a comprehensive doctrine can be reached in the way that Rawls discusses it is if the comprehensive doctrines have already become, to some degree, comprehensively liberal. We can see where his critique takes root in Rawls's system. When the distinct groups of comprehensive doctrines in society begin to share similar intuitions and values that allow them to come to a political conception of justice, then Barnhart says they are already liberal because they are entering into the discussion in a liberal way. In order for an individual to participate in a purely political discussion with purely political values, that individual must conceive of herself as a rational being who is free, equal, and abstracted from his own ends in a Kantian sense. ${ }^{21}$ An individual with a conception of the self that denies that this kind of abstraction or freedom is possible, cannot participate in the political debate, and so Barnhart accuses Rawls of being "metaphysically regulative."22 Barnhart asks us to imagine a Hindu person who believes that there is no self to think of. What would it mean to ask such a

21. Michael Barnhart, "An Overlapping Consensus: A Critique of Two Approaches," The Review of Politics 66, no. 2 (2004): 262.

22. Ibid., 263. 
person to participate in a purely political debate where we imagine an individual stripped of all identifying features? If the Hindu person joins the debate, then something is lost from the individual's comprehensive doctrine in order to facilitate his participation in society. For such an individual, valuing social cooperation in the same way that Rawls does means losing a unique constitutive element of the comprehensive doctrine. The society that has such an overlapping consensus is not truly pluralistic for Barnhart.

Barnhart retells Rawls's historical narrative, but frames it as the story of a society antagonistic to, rather than accepting of, multiculturalism. It is a society that robs groups of their unique features so that they can truly accept the principles which they uphold in the political part of their life. As Rawls says, the groups in society will come together for a modus vivendi at first. Slowly, the groups value the resulting cooperation and then begin to value the agreed-upon political conception of justice for its own sake, and then the political values become part of the individual comprehensive doctrines. What this really amounts to, contends Barnhart, is that the older generations which formed the modus vivendi never fully take on the political values they agree to, but later generations do adopt the values of the dominant political culture. ${ }^{23}$ Just as Rawls describes, the comprehensive doctrine of the group slowly internalizes the political values. However, this is not truly an acceptance or discovery of moral allegiance. Rather it is the whittling away of the comprehensive doctrine's distinguishing features as younger generations abandon the practices and values of their elders. In his words, Barnhart claims that "the young adopt the values of the dominant political culture while the old never fully integrate such values, taking their moral traditional commitments with them as they

23. Barnhart, "Critique of Two Approaches," 264. 
die." ${ }^{24}$ A society that follows Rawls's overlapping consensus is not pluralistic in any significant or valuable way. For Barnhart, Rawls’s overlapping consensus becomes a melting pot where unique attitudes and modes of thought become comprehensively liberal so that they may adequately participate in the state.

Barnhart is claiming that any liberal stance is inextricably linked to many metaphysical commitments, and thus requires comprehensive beliefs that go beyond the political. Earlier, we saw Rawls explicitly deny this, and I think it is possible to have a political conception of the person independent of metaphysical demands. Conceiving of a person as politically free and equal does not necessitate an understanding of 'free' and 'equal' that goes beyond the political context. When we say someone is free in the political sense we can just mean capable of deciding things for themselves without interference, and we do not begin by learning about a metaphysically independent self before we have this concept of choice-making. Barnhart's critique is then not going to defeat Rawls unless he can provide better evidence for why this Kantian self is necessarily tied to Rawls's liberal citizen. Even if it does not go as far as to make individuals comprehensively liberal, this critique does highlight potential issues facing groups trying to integrate with a larger political culture, that Rawls does not address. Liberal societies value pluralism and cultural distinctiveness insofar as they set up rights to protect free thought and expression. Groups which feel incapable of expressing themselves without referring to justifications that already exist in a society they feel distant to, can become alienated and forgotten. Indigenous people in Canada often equate leaving reserves and becoming contributing members of a more centralized Canadian

24. Barnhart, "Critique of Two Approaches," 264. 
city, to a loss of culture. Participating in politics and society on the Canadian government's terms was the final goal of the old project of cultural genocide.

\section{3}

Charles Taylor offers us many conceptual terms to help us determine in what ways the state should remain neutral. In 1999, Charles Taylor wrote on how we could reach a form of overlapping consensus on human rights. He called it an 'unforced consensus,' and it began in a very different place than did Rawls's overlapping consensus. Taylor began with how the world is today and looked at the ways in which open discussions between groups could bring about agreement on human rights. He wanted to show that different groups could come to support the same principles of human rights, from very different premises. Perhaps most importantly, Taylor distinguishes mutual understanding from consensus, and argues that while they may not come about successively, both are needed. ${ }^{25}$ For Taylor, the valuable consensus that is sought can only be achieved through such a discussion. The various adherents to comprehensive doctrines must seek agreement by making reference to their own beliefs. This does not need to lead to founding the political values of the society in one comprehensive doctrine in particular. Rather, it will lead to consensus when every group involved can see that the other comprehensive doctrines are equally reliable in supporting the agreed upon political values. Taylor is not falling into relativism, nor is he allowing the political values of the society to be determined by which majority comes into power. He is seeking consensus

25. Charles Taylor, "Conditions of an Unforced Consensus on Human Rights," in The East Asian Challenge for Human Rights, ed. Joanne Bauer and Daniel Bell (Cambridge: Cambridge University Press, 1999), 138. 
on norms of human rights, after all. He is building a founding principle of justice. The consensus on political principles is still there, and still valued. However, it is not merely instrumentally valuable, and it is valued alongside mutual understanding. It is still an overlapping consensus, and it achieves the same moral allegiance to the state. The difference lies in the approach taken by Taylor, and how an emphasis on mutual understanding can lead us to the overlapping consensus in a better way.

Taylor emphasizes that debate involving the cultural traditions of groups will necessarily involve every party accepting some change to their views, and working to make the various belief systems capable of agreement. Taylor states that "world convergence will not come through total loss or denial of traditions all around, but rather by creative reimmersions of different groups, each in their own spiritual heritage, traveling different routes to the same goal."26 Jay Drydyk draws our attention to Taylor's use of the word 'convergence.' Drydyk argues that while Taylor claims to be reaching a kind of consensus akin to Rawls, the convergence that Taylor seeks is actually significantly different. Drydyk states that "[a] strategy of convergence allows a conclusion to be derived from premises that not everyone shares, whereas a strategy of consensus requires the conclusion to be derived from premises that are shared." 27 In other words, while Rawls needs the constituent groups in society to internalize the political values as their own, and then cut off their private comprehensive doctrines from the debate, Taylor's model of convergence allows for agreement coming out of many different sources. Taylor respects the various traditions and cultures that are attempting to

26. Taylor, "Unforced Consensus," 144.

27. Jay Drydyk, "Two Concepts of Overlapping Consensus," in Human Rights: India and the West, ed.AshwaniPeetush and Jay Drydyk (New Delhi: Oxford University Press (India), 2015), 82, n. 4. 
agree on political principles by allowing their beliefs to enter into the public debate. Over a decade later, Taylor, with Jocelyn MacLure, gives us more ways to discuss this in his book on secularism.

Taylor and MacLure claim that, in the past, religion was always used for developing national unity and moral allegiance to the state (or King). After the reformation, modes of secularism emerged; however, this often led to instances of societies going to another extreme and fashioning civic unity through a kind of state morality. Taylor and MacLure go on to argue that "the presence of what Rawls calls an 'overlapping consensus' about the basic public values is the condition for the existence of pluralist societies." ${ }^{28}$ They believe that Rawls is right, and that an overlapping consensus is the only way to create moral allegiance in a pluralist society. They directly take on many of Rawls's critics. Secularism is set out by the authors in terms of neutrality of the state. To be secular, the state must remain neutral on moral issues and respect people's abilities to deal with their own moral issues. In their words: "The state recognizes the individual agent's ultimate authority over the set of beliefs that will allow him or her to interpret the world and his or her place in it and to exercise the faculty of judgment when facing dilemmas of a moral nature or those related to his or her identity." ${ }^{29}$ Taylor and MacLure go on to say: "A liberal and democratic state cannot remain indifferent to certain core principles, such as human dignity, basic human rights, and popular sovereignty. ${ }^{30}$ For Barnhart, these statements are incompatible. You cannot give individual agents ultimate authority so long as you are beginning by instilling certain

28. Jocelyn Maclure and Charles Taylor, Secularism and Freedom of Conscience (Cambridge: Harvard University Press, 2011), 12.

29. Ibid., 10-11.

30. Ibid., 11. 
values into them. Barnhart is calling the project of the overlapping consensus circular, but again his critique falls flat because the goal of the consensus is to begin with those values and then to demonstrate why they are a good idea. Barnhart's real concern seems to be a fear that cultural practices, largely valued intrinsically, will be lost if we are constantly bringing the various comprehensive doctrines more in line with liberalism and less in line with their own traditions. This is not only a potential problem if immigrants or older generations feel out of touch with political justifications, but Barnhart is also worried that the state is encouraging people to become alienated from their traditions.

Interestingly, Taylor and MacLure distinguish between two types of secularization: political secularization and social secularization. The difference, they say, is "that political secularization is the process by which the state affirms its independence from religion, whereas one of the components of social secularization is an erosion of the influence of religion in social practices and in the conduct of individual lives." ${ }^{31}$ This distinction is useful, because it allows us to see the real fears behind critiques of Rawls. In the western world we tend to take political secularization, seen just as the state's independence from outside religions though not necessarily exclusion of it, as a given. However, it is easy to see why social secularization does not value or respect pluralism in a meaningful way. As well, if we look back to Barnhart's examples of how Rawls's overlapping consensus erodes comprehensive doctrines into doctrines that are comprehensively liberal, we can see that this is another manifestation of his real fear. A liberal political conception of justice becoming more important to citizens than their comprehensive doctrines through a process akin to what Rawls describes, could lead to a 
loss of importance for the traditions and doctrines long held by cultural groups in society. If Rawls completely bans people's comprehensive doctrines and conceptions of the good from the public realm, and expects them to take in the political beliefs as their own so as to facilitate cooperation, then it seems that this could lead to social secularization; namely, people's beliefs lose power and meaning in the private sphere because of policies set up in the public sphere. What is even more interesting is that Taylor and MacLure also state that a degree of this phenomenon is inevitable. They claim that:

neutrality on the state's part will not impose an equal burden on all citizens. The liberal state ... defends the principle that individuals are to be considered autonomous moral agents, free to define their own conception of the good life. In schools ... the state will favour the development of student's critical autonomy. In exposing students to a plurality of worldviews and modes of life, the democratic and liberal state makes the task more difficult for parents seeking to transmit a particular order of beliefs to their children and even more difficult for groups wishing to shield themselves from the influence of the larger society in order to perpetuate a style of life based more on respect for tradition than on individual autonomy and the exercise of critical judgment. ${ }^{32}$

Essentially, to the degree that state institutions must favour autonomy as the foundation of what makes their pluralism possible, the state cannot remain neutral. The state must behave in a way seemingly counter to pluralism in order for pluralism to flourish. Thus far, Taylor seems to be defending Rawls, and it makes sense that he would. Taylor is still using an overlapping consensus model. Yet, it is still important to see Taylor's consensus in terms of convergence emerging from mutual understanding. In this light, we can see Taylor avoiding many of the social secularization issues to which Rawls might be vulnerable. If comprehensive doctrines can be used in the public discourse and are freely discussed, then there is no reason for the society to erode them. The important difference we can see begin to emerge, is that Taylor does not develop a strict public reason guideline the way that Rawls does. 
Taylor and MacLure also discuss secularism in terms of its ends and its operative modes. They argue that much of the confusion surrounding the debate on secularism comes from confusing the operative modes of secularism with these ends. They state: "In our view, secularism rests on two major principles, namely, equality of respect and freedom of conscience, and on two operative modes that make the realization of these principles possible: to wit, the separation of church and state and the neutrality of the state toward religions.. ${ }^{33}$ The separation of church and state, they claim, is often taken as a principle of secularism, or as simply the definition of secularism. They argue that this confuses the issue because separation of church and state is not sufficient to ensure secularism. The state can become entirely cut off from religion to the point where it creates a public ethos of atheism and puts religious people at a disadvantage. This is not secularism, because the state is not neutral. If the state is giving advantage to one group over another, then it is not secular. The ends of secularism do come into conflict with the modes, as well. Taylor and MacLure give the example of a teacher in a public school wearing a headscarf. This is a conflict "between respect for moral equality and the protection of freedom of conscience and religion. ${ }^{״ 34}$ They argue that a teacher displaying this kind of religious symbol can eliminate the neutrality of the school, but banning such symbols is harming the freedom of that individual's conscience. The problem demonstrates that simple neutrality is not enough to cover every instance, and that managing and respecting pluralism is not a simple thing. The authors seem to favour the idea of protecting the ends of secularism over the means, as this is what they characterize

33. Maclure and Taylor, Secularism, 20.

34. Ibid., 24. 
as a more liberal approach. An approach to secularism that focuses on a strict adherence to the means of secularism is what they characterize as a more republican approach.

Taylor and MacLure argue that those strict forms of republican secularism come to grant a great deal of importance to the means of secularism and elevate them into values of their own. They say: "That could be called a 'fetishism of means': the separation of church and state and the state's religious neutrality become values that must be defended at all cost rather than means that, though essential, are to be defined as a function of the ends they serve. ${ }^{, 35}$ Societies that follow this mindset attribute other ends to secularism, "namely, the emancipation of individuals and civic integration." ${ }^{.36}$ In contrast, an outlook that focuses solely on the ends stated above and favours freedom of conscience over the strict separation of church and state, is a more liberal outlook. It is unclear where the authors believe that Rawls's approach lies. They have said that an overlapping consensus is the foundation that makes any of these forms of secularism possible, but they characterize an emphasis on "civic integration" as a fetishizing of the means and a non-liberal approach to secularism. The previously-discussed critiques of Rawls show how he tends to emphasize moral allegiance over valuing pluralism in and of itself. In this sense, Taylor's approach has a greater emphasis on freedom of conscience, since it allows individuals to bring their comprehensive doctrines into the public sphere. Again, the problem does not seem to be an overlapping consensus as being necessarily restrictive, but with Rawls's public reason focusing on a neutrality of means.

The last thing that Taylor and MacLure give us to consider right now is two ways to discuss what we really mean by 'public.' The first meaning of 'public' comes from the 
Roman use of the word, and refers to what is of importance to society "in opposition to what regards 'private' citizens. ${ }^{, 37}$ The way we discuss 'public interest' comes from this meaning, and we use public this way in reference to institutions, because "in principle, public institutions serve the common good. ${ }^{38}$ The second meaning refers to "what is open, transparent, and accessible, in opposition to what is secret," and this comes from the eighteenth century. ${ }^{39}$ When we discuss the public sphere and we mean this kind of public, we generally mean places for discussion that are open to any private citizens to join. ${ }^{40}$ Thus, if we wish to remain neutral in the public sphere, we have to define what we mean by 'public'. Neutrality in public institutions can be a positive, or even necessary, guideline. As has been discussed, this goes a long way in ensuring pluralism has even a chance to flourish. If we mean that public spaces in general must be completely free of any reference to religion or comprehensive doctrines, then perhaps we have taken neutrality to the point of violating freedom of conscience.

What is of importance to the project at hand is determining in what sense Taylor and Rawls mean the word 'public' in their overlapping consensus frameworks and the ways in which they lay out the boundaries of public reason. Rawls would seem to limit his use of the word 'public' to public institutions. This distinction is not completely clear cut. A school, in reference to the above example, is a public space in both senses of the word. In Canada's House of Commons, the Members of Parliament would be part of a public institution, but any citizen watching the proceedings from another room would be in a public space of the second kind. When Rawls discusses public reason, does he mean

37. Maclure and Taylor, Secularism, 36.

38. Ibid., 37.

39. Ibid.

40. Ibid. 
limiting those who work within the basic public institutions to not mentioning their comprehensive doctrines, or is he afraid of any form of public debate centering on comprehensive doctrines? Rawls will set out a more solid understanding of where public reason must be followed in society, but we will see that it is still not perfectly clear. Regardless, this is not a problem Taylor faces. His search for mutual understanding allows any public realm the ability to discuss the comprehensive doctrines held by citizens. Drawing the lines between the public and private spheres is of utmost importance, because Rawls relies on this distinction. The fact that the distinction is so much more important to Rawls than to Taylor, though, shows that Taylor leaves more room for freedom of conscience.

Despite all these criticisms, it is possible to frame Rawls in a more forgiving light. When Rawls assumes a certain moral psychology, he is not setting out a metaphysical claim about the nature of the self. In Rawls's mind, he is simply stating a fact about how humans will develop given a liberal society. Rawls assumes a moral psychology in which human beings naturally seek fair terms of association through reasonable terms. ${ }^{41}$ Part of the debate that surrounds Rawls has to do with what he considers to be a reasonable comprehensive doctrine in terms of public reason. If religion can never be considered reasonable, then he may favour an extreme form of secularism. Rawls could say that as reasonable people always seeking fair terms, it does not matter if society incentivizes a change in our values, because they are changes that were likely to happen naturally. Rawls does not think that reason can lead us to an ultimate end or value for society, which is why we have to deal with the fact of pluralism and balancing state neutrality. On

41. Rawls, "Overlapping Consensus," 22. 
the other hand, he sets out what he deems to be reasonable conditions of fair cooperation that anyone could agree to. Everyone naturally seeking reasonable and fair terms, and coming together to outline such terms, seems to say that we can at least reach political ends with which most people would agree. The caveat would be that this can, in no way, tell us how one should morally live his or her life. These political ends, however, seem to also be in line with the moral doctrines to achieve an overlapping consensus. In the end, it is unclear how far reasonableness can get us.

Taylor clearly endorses the political ends of liberalism, at least in terms of commitments to human dignity and human rights, and he would seek to foster a similar moral psychology as Rawls. There would, however, be important differences, such as an emphasis on mutual understanding, between the two. Taylor even emphasizes how different traditions would round each other out and help each other come to an agreement. This seems to mean that some parts of comprehensive doctrines can be seen as more reasonable or legitimate than others. The state or society is neutral, in that it does not favour or ground its chief political conceptions of justice in one comprehensive doctrine over another, but it emphasizes freedom of conscience by allowing for convergence on these political conceptions. It does this by making mutual understanding as a key goal for society in the fostering of a moral psychology, conducive to creating a stable, overlapping consensus.

Rawls's overlapping consensus is an important idea, because some form of moral allegiance to the state is necessary. The problems that emerge, however, are not minor. Many of the critiques come down to a fear of some form of cultural imperialism, or alienation from the political sphere. The next chapter will focus on Rawls's idea of public 
reason and will examine further critiques that place exclusion of ideas or people as a primary problem for Rawls. The way in which we engage in public debate helps to shape the values of any society. How we come to an overlapping consensus, and what emphasis is put on understanding versus agreement, determines to what degree we respect and value pluralism. 


\section{Public Reason}

Is John Rawls's idea of public reason restrictive to the point of causing harm to certain groups in society? By 'harm', in this instance what I mean is, does Rawls's account of public reason lead to certain groups being left out of the political discussion in society? Does it lead to easier access for people with certain comprehensive doctrines? I have examined Rawls's overlapping consensus, but many of the critiques aimed at that aspect of Rawls's work are also aimed at what Rawls says about public reason. In important ways, the boundaries for public reason are set by the overlapping consensus. The premises that everyone agrees to are those political principles which an overlapping consensus will connect to the various comprehensive doctrines of society. What the constituent members of society agree upon in the political realm forms the consensus, and from these principles we formulate the premises available to us for debate. However, even if a society has formed an overlapping consensus in the way Rawls expects a wellordered society to do, is his form of public reason necessary?

This chapter will begin with a careful examination of Rawls's account of public reason in his work "The Idea of Public Reason Revisited". This work contains many important updates made by Rawls, as well as responses to prevalent critiques made since the introduction of his overlapping consensus and his idea of public reason. Then I will examine critiques made by Jeremy Waldron, who argues that Rawls does not allow for new ideas to enter into public debates. To answer this criticism, Rawls can readily show how new ideas can join public debate by translating them to the principles of the basic structure of society. Next, I will look at instances where translation was not enough, and practicing public reason could lead to political alienation. Lastly, I will discuss Susan 
Moller Okin's feminist critique of Rawls as it applies to public reason. Her critique shows how Rawls must give a better accounting of how citizens develop the proper moral psychology to allow for any agreement on the principles that make up the basic structure of society, on which the overlapping consensus is reached.

\section{1}

The idea of public reason for Rawls is a basic feature of any democratic society, as it applies to the formation of constitutional essentials and the forming of legislation. Any well-ordered democratic society will encounter "the fact that a plurality of conflicting reasonable comprehensive doctrines, religious, philosophical, and moral, is the normal result of its culture of free institutions. ${ }^{, 42}$ Rawls argues that citizens in such a society will acknowledge that they cannot find agreement through references to their varied comprehensive doctrines and instead will look for a way to find agreement using rules of justification that all can accept. ${ }^{43}$ To answer this question Rawls says: "I propose that in public reason comprehensive doctrines of truth or right be replaced by an idea of the politically reasonable addressed to citizens as citizens. ${ }^{, 44}$ When Rawls advises us to think of people as citizens, he means to consider them to be reasonable, free, and equal. $\mathrm{He}$ says that "we think of persons as reasonable and rational, as free and equal citizens ... and having, at any given moment, a determinate conception of the good, which may change over time. ${ }^{45}$ In dealing with public justification, we must give reasons that any

42. John Rawls, "The Idea of Public Reason Revisited," in The Law of Peoples (Cambridge: Harvard University Press, 1999), 131.

43. Ibid., 132.

44. Ibid.

45. Ibid., 171. 
citizen could understand and accept as reasonable, independent of their class, race, or any other feature or interest. ${ }^{46}$ Rawls wants us to go beyond tailoring our reasoning to the interests of specific groups because this strategy cannot give us truly "shareable" reasoning. ${ }^{47}$ Even though "at some point we must take these interests into account," Rawls says we must put aside any conception of personhood that relies on comprehensive doctrines or even on accounts of human nature and "rely on a political conception of persons as citizens instead." ${ }^{49}$ Public reason is about finding a way for the coercive use of force to be justified in a way that all people in society, conceived as purely political citizens, can accept.

Public reason applies only to what Rawls calls the public political forum and not to the civil society within the democratic state, which Rawls calls 'the background culture.${ }^{50}$ In "The Idea of Public Reason Revisited", Rawls is very careful to distinguish the background culture from the public political forum, since he believes that many critiques of public reason are a result of public reason being inappropriately applied to the background culture. ${ }^{51}$ The background culture can contain any number of non-public reasons and comprehensive doctrines, and it is where citizens can take full advantage of their freedom of speech or expression. Rawls is very careful to say that public reason imposes a moral duty and not a legal duty, because if public reason imposed a legal duty, it would conflict with freedom of speech. ${ }^{52}$ The public political forum is the venue where public reason must be applied for Rawls, and is made up of three parts. These three parts

46. Rawls, "Public Reason Revisited," 171.

47. Ibid., 172.

48. Ibid., 171.

49. Ibid., 172.

50. Ibid., 133.

51. Ibid., 134.

52. Ibid., 136. 
are: "the discourse of judges in their decisions and especially of the judges of a supreme court; the discourse of government officials, especially chief executives and legislators; and finally, the discourse of candidates for public office and their campaign managers, especially in their public oratory, party platforms, and political statements." ${ }^{, 53}$ It would seem, then, that the government, and those seeking to operate directly as the government, primarily possesses the duty to present purely public reasons. The structure of the idea of public reason does seem to suggest this; however, when Rawls distinguishes the idea of public reason from the ideal of public reason, the issue becomes more complicated.

The structure of the idea of public reason has five important elements. Ignoring these elements renders the idea of public reason "implausible, as it does when applied to the background culture. ${ }^{, 54}$ The five aspects of the idea of public reason are:

(1) the fundamental political questions to which it applies; (2) the persons to whom it applies (government officials and candidates for public office); (3) its contents as given by a family of reasonable conceptions of justice; (4) the application of these conceptions in discussions of coercive norms to be enacted in the form of legitimate law for a democratic people; and (5) citizens' checking that the principles derived from their conceptions of justice satisfy the criterion of reciprocity. ${ }^{55}$

The fundamental political questions mean "constitutional essentials and matters of basic justice. ${ }^{, 56}$ By these terms, Rawls means that public reason applies when government officials are deciding what can reasonably be included in the written constitution, as well deciding on matters that relate to the basic structure of society but are not typically included in constitutions, such as "basic economic and social justice., ${ }^{, 57}$ Rawls is not saying that public reason is a one-way relationship. It is not merely a means by which a

53. Rawls, "Public Reason Revisited,"133-134.

54. Ibid., 133.

55. Ibid.

56. Ibid.

57. Ibid., 133, n. 7. 
government's reason can be judged by citizens. Rawls states: "the idea of public reason specifies at the deepest level the basic moral and political values that are to determine a constitutional democratic government's relation to its citizens and their relation to one another. ${ }^{, 58}$ The political relationship that is forged through public reason applies to all citizens through the ideal of public reason. The structure of the idea of public reason gives strict guidelines for where and how it can be applied. The ideal of public reason is looser, but it is also what imposes Rawls's duty of civility on all members of society. This moral duty is fulfilled when the ideal of public reason is realized. ${ }^{59}$ At first, Rawls says that this happens "whenever judges, legislators, chief executives, and other government officials, as well as candidates for public office, act from and follow the idea of public reason and explain to other citizens their reasons for supporting fundamental political positions in terms of the political conception of justice they regard as the most reasonable. ${ }^{, 60} \mathrm{He}$ goes on to say, however, that every citizen fulfils their duty of civility when they imagine themselves to be legislators or officials and argue and vote as if they were holding themselves to the idea of public reason. Thus, citizens have not only a moral duty to hold legislators and officials to the idea of public reason, but also to hold themselves and others to that ideal. ${ }^{61}$

The third aspect of the idea of public reason is the content of public reason, which must make reference to an ordered conception of justice. Rawls wants the political values expressed by political conceptions of justice to be freestanding and "not puppets

58. Rawls, "Public Reason Revisited," 132.

59. Ibid., 135.

60. Ibid.

61. Ibid., 135-136. 
manipulated from behind the scenes by comprehensive doctrines."62 For Rawls "the significance of completeness lies in the fact that unless a political conception is complete, it is not an adequate framework of thought in the light of which the discussion of fundamental political questions can be carried out." ${ }^{, 63}$ Rawls is concerned with the possibility of real debate stemming from political conceptions of justice. His entire project is aimed at ending what he sees as the inevitable deadlock that is caused by arguing from comprehensive doctrines. He is not looking for citizens to make their comprehensive doctrines into political terms, but rather feels that citizens need to make a concerted effort to formulate political conceptions of justice that overlap with their own comprehensive doctrines but are distinct from them. Political conceptions of justice are given three main features by Rawls to ensure completeness:

First, a list of certain basic rights, liberties, and opportunities (such as those familiar from constitutional regimes);

Second, an assignment of special priority to those rights, liberties, and opportunities, especially with respect to the claims of the general good and perfectionist values; and Third, measures ensuring for all citizens adequate all-purpose means to make effective use of their freedoms. ${ }^{64}$

Rawls argues that any political conception of justice with these characteristics will see citizens as free and equal and "society as a fair system of cooperation over time." ${ }^{\circ 5}$ Here, Rawls is showing the potential for disagreement among the content of public reason. Even if all liberal political conceptions of justice have the same list of rights stemming from a common belief in the constitution (or an overlapping consensus in society), how individuals decide to order those values, or what needs to be made available to

62. Rawls, "Public Reason Revisited," 145.

63. Ibid.

64. Ibid., 141.

65. Ibid. 
individuals, is still debatable. Shortly after, though, Rawls gives three more features of a political conception of justice:

First, their principles apply to basic political and social institutions (the basic structure of society);

Second, they can be presented independently from comprehensive doctrines of any kind (although they may, of course, be supported by a reasonable overlapping consensus of such doctrines); and

Finally, they can be worked out from fundamental ideas seen as implicit in the public political culture of a constitutional regime, such as the conceptions of citizens as free and equal persons, and of society as a fair system of cooperation. ${ }^{66}$

All six features are aimed at distinguishing political conceptions of justice from comprehensive doctrines. Public reason is meant to argue with reference to free-standing political values. The content of public reason is whatever complete set of premises can be reasoned from ideas basic to any functioning democracy, or from the public political culture that can be seen as the overlapping consensus of a society. If an overlapping consensus occurs when groups within society come to appreciate the same political values based on different comprehensive doctrines, then the content of those shared political values and how to order those values would seem to be a proper starting point for public reason.

A final important addition to the content of public reason is Rawls's proviso. Rawls states: "reasonable comprehensive doctrines, religious or nonreligious, may be introduced in public political discussion at any time, provided that in due course proper political reasons - and not reasons given solely by comprehensive doctrines - are presented that are sufficient to support whatever the comprehensive doctrines introduced are said to support." ${ }^{, 67}$ How the proviso is to be met, namely when the public political reasons need to be presented or in what way, or by whom, Rawls does not say. Rawls

66. Rawls, "Public Reason Revisited,"143.

67. Ibid., 152. 
asks those questions but argues that they must be worked out from within each society's individual public political culture. ${ }^{68}$ Rawls goes on to say that the same rules govern the content of the public reasons presented in the proviso, but when presenting your comprehensive doctrine before satisfying the proviso, there are no rules on how to do this. ${ }^{69}$ This is the biggest change to Rawls's approach to public reason in "The Idea of Public Reason Revisited". Rawls is attempting to avoid the accusation of exclusion without losing or lessening the importance for political or public justifications. How effective Rawls's proviso is at accomplishing this is not immediately clear.

Everything in Rawls's idea of public reason rests on, and is limited by, the criterion of reciprocity. Reciprocity means that the coercive power of the state is used justly when the reasons given for the use of that power were given in such a way that they were reasonably expected to be accepted by all citizens, so long as others do so as well. We have seen that public reason is a relation between citizens, and Rawls gives democratic "citizenship two special features: first, it is a relation of free and equal citizens within the basic structure of society, a structure we enter only by birth and exit only by death; and second, it is a relation of free and equal citizens who exercise ultimate political power as a collective body." ${ }^{70}$ What Rawls means by "enter only at birth" raises questions for immigrants entering a democratic society. In the structure of public reason, we are meant only to consider people as citizens, which means as neutral, in the political sense, free and equal persons. Yet, emphasizing citizens' equal claim to collective political power is what brings about the problems Rawls sees in the fact of reasonable

68. Rawls, "Public Reason Revisited,"153.

69. Ibid.

70. Ibid., 136. 
pluralism. The criterion of reciprocity ties everything together as the final test for the idea of public reason. Rawls even defines a reasonable citizen as one who is willing to follow this criterion. He says:

Citizens are reasonable when, viewing one another as free and equal in a system of social cooperation over generations, they are prepared to offer one another fair terms of cooperation according to what they consider the most reasonable conception of political justice; and when they agree to act on those terms, even at the cost of their own interests in particular situations, provided that other citizens also accept those terms. ${ }^{71}$

Essentially, citizens are reasonable when they make proposals that they can reasonably expect others to follow and reasonably accept. If political conceptions proposed through public reason follow its structure, and the content of the reasons are based on complete and reasonable political conceptions in the sense outlined above, then Rawls believes reasonable citizens will see proposed conceptions of justice as legitimate despite a strong preference for their own conception. ${ }^{72}$ This feeds into Rawls's idea of legitimate law.

Legitimate law is the result of public reason guided by reciprocity. Laws are only legitimate when they come from reasons all can be expected to accept, or else power is being misused. For Rawls, this means that all government officials (to which the idea of public reason applies directly) vote in line with the idea of reciprocity, and all citizens vote for these officials as if they were ideal legislators (thus fulfilling the ideal of public reason and their civic duty), and any law resulting from the majority vote becomes legitimate. ${ }^{73}$ Reciprocity also grounds Rawls's conception of political legitimacy, as he states that the "exercise of political power is proper only when we sincerely believe that the reasons we would offer for our political actions ... are sufficient, and we also

71. Rawls, "Public Reason Revisited,"136.

72. Ibid., 137.

73. Ibid. 
reasonably think that other citizens might also reasonably accept those reasons." ${ }^{74}$ Our willingness to see others as citizens in the Rawlsian sense is then crucial to everything. All of democracy seems to rest on the idea of public reason, for without a framework on how to justify power, no use of that power is legitimate. Rawls has said from the outset that public reason applies to well-ordered constitutional democracies, but he also emphasizes that it is an element of deliberative democracies. ${ }^{75}$ Any deliberative democracy will have some form of public reason, a constitution outlining the structure of legislative bodies and public deliberative forums, and citizens willing to follow public reason and "realize its ideal in their political conduct."76

Rawls argues that any political conception which seeks to have the truth or their conception of the right be dominant over others, is unreasonable and cannot exist in the public debates of a healthy democracy. ${ }^{77}$ Thus the idea of public reason is meant to be exclusionary in important ways. The challenges to Rawls's idea of public reason that we will look at below do not mean to imply that democracy does not need some form of limits on public reason. Democracies do require a political culture that is made up of groups willing to work with one another. What is very much debatable is whether or not Rawls's idea of public reason is truly the best way to reach cooperation. If reasonable comprehensive doctrines are entered into public debate as justifications rather than as explanations under the proviso, will the ensuing debate truly lead to political gridlock? Is it at least plausible that a political culture of mutual acceptance and cooperation can be fostered through public debate with comprehensive doctrines? These questions, however,

74. Rawls, "Public Reason Revisited," 137.

75. Ibid., 138.

76. Ibid., 139.

77. Ibid., 138. 
are only salient if there is a problem with Rawls's idea of public reason such that we have reason to search for an alternative. I look now to the varied critiques of public reason.

\section{2}

Jeremy Waldron's chief complaint with Rawls's idea of public reason was originally that it denied the possibility of truly new ideas emerging from public debate. Waldron is concerned that Rawls's idea of public reason only "offers ... an overly narrow conception of the matrix of public reason." ${ }^{78}$ Here Waldron is taking an idea from Aristotle. Waldron conceives of the Aristotelian model of public deliberation as one based on "a common matrix of public understanding", which ultimately means that people within a community need to be open and able to understand and receive ideas before deliberation can proceed. ${ }^{79}$ He contrasts this idea with John Stuart Mill's account of public deliberation in which ideas, or personal truths, are set into the public forum, and battered against other ideas until a complete truth emerges. ${ }^{80}$ The point of bringing these views to light is that Waldron thinks the liberal worry that the fact of pluralism leads to insurmountable disagreement is "exaggerated" and that "we should not underestimate the human capacity to conduct conversations even in these unpropitious circumstances." ${ }^{81}$ Even though Waldron says, or at least heavily implies, in multiple places, that the Aristotelian model is more akin to the way people actually participate in public debate, and even goes on to note how the Aristotelian model can easily be linked to liberal accounts of deliberation,

78. Jeremy Waldron, "Religious Contributions in Public Deliberation," San Diego Law Review 30, no. 4 (1993): 837.

79. Ibid., 836.

80. Ibid.

81. Ibid., 835. 
he uses Mill's account as evidence that some grounds of shared understanding are not strictly necessary for agreement in society. ${ }^{82}$ Waldron wants us to consider the possibility of people desiring to have their opinions challenged, in a way that he does not think Rawls will allow. Waldron quotes Rawls's initial formulation of public reason as coming "from premises that we and others recognize as true, or as reasonable for the purpose of reaching a working agreement. ${ }^{\prime 83}$ From this, as well as from Rawls's assertion that public reason also comes from shared knowledge, common sense, and science, Waldron concludes that while the liberal idea of public reason rests on a matrix of public understanding, and in some sense reflects how people give public justification (by this he means people assume that others will be capable of understanding their reasons), the idea of moving from shared premises does too great a disservice to public deliberation and society as a whole.

Waldron's argument can be responded to in a number of ways by Rawls. The argument rests on the idea that moving from shared premises from within the political culture is too limiting, but the reasons he gives for why they are limiting mainly apply to the background culture. Waldron begins his work by discussing a Pastoral Letter published by a group of Catholic bishops. ${ }^{84}$ His goal is to show that religious debates on issues like social or economic justice have a place in political debate. He argues that the bishops are not merely addressing the letter to Christians for the sake of guiding their private life. Rather the bishops, according to Waldron, fully intend for this letter to

82. Waldron, "Religious Contributions," 837.

83. Rawls, "Overlapping Consensus," 6.

84. Waldron, "Religious Contributions," 817. 
inform the political decisions of people, and not just Christians. ${ }^{85}$ Waldron argues that "the bishops are, in other words, in the same game as philosophers who write about justice" (emphasis his). ${ }^{86} \mathrm{He}$ intends to show that the bishops' letter then has a place in political discourse because of the universalism of its recommendations. He goes on to say that the letter is even more applicable to political discourse than that of any content coming out of Rawls's public reason, because of its intended universality rather than the relativism he sees in Rawls. ${ }^{87}$ Here I take Waldron to mean that the bishops try to appeal to all people as people, whereas Rawls can only take reasons from those already present in any given society's culture. He is arguing that the reasons for any conception of justice given by the bishops are superior to any given by Rawls because of their universal application, and that this justifies them as part of the political discourse and not just as giving reasons that only Christians could accept. Simply put, none of this would matter to Rawls because the bishops' letter belongs to the background culture. It is not debate done in any of the three parts of the public political forum. Waldron wants to say that the bishops are having meaningful political debates that are capable of convincing anyone, despite not following the guidelines of public reason. Even if this were true, Rawls never says that citizens could not have these kind of productive debates. They just need to happen in the background culture.

What the proper topic for the background culture is, is by no means clear. Rawls argues that the background culture is civil society and has to do with essentially anything outside of the public political forum. The background culture even includes public

85. Waldron, "Religious Contributions," 825.

86. Ibid.

87. Ibid. 
debates on these issues so long as those debating them are not government officials. Still, the reasons gained from these kinds of debates made by private citizens then cannot be used in voting by citizens because a citizen's duty of civility demands that they imagine themselves as legislators, and only accept and form reasons that could be accepted by any citizen. In this sense then, Waldron has cause to worry about how narrow public reason is for Rawls, because it is at least somewhat unclear when citizens are arguing in the freedom of the background culture, and when they must fulfill their duty of civility. For instance, if I, as a citizen with no position in government, were to casually recommend to someone, in a non-public forum, that they vote for a political party because that party has strong support for purely Christian ideals, I could be seen as failing my duty of civility despite the conversation being purely in the background culture. Both the idea that our beliefs need to be challenged, and the idea that humans enjoy being faced with a purely new idea and being struck by how right they are, or by how it changes our view of the world, is what Waldron fears losing. ${ }^{88}$ He gets these points from his Mill example, and uses it to push most of his argument for a public reason that is far more inclusive than what Rawls wants. These are Waldron's chief concerns, that Rawls cannot give us good ways to challenge or change our views. If we truly can only begin with a static set of premises that society has some previously to, then reasoning will be done along stagnant and repetitive lines.

Perhaps the more convincing way that Waldron goes about arguing for including something like the bishops' letter in public political debate is by challenging the distinction between government officials and normal citizens. He argues that this

88. Waldron, "Religious Contributions," 842. 
distinction is relied upon for neutrality in liberal thinking, but ultimately fails. ${ }^{89}$ Citizens, by voting, hold as much or more political power than public officials, and because of this Waldron argues that if public officials must give neutral reasons because of the power they hold, so must voters. ${ }^{90}$ He accepts that public officials may hold more power and as such more moral responsibility in certain instances, but ultimately maintains that if the ability to oppress others is what gives public officials a special claim to neutrality, then voters must be held to the same standard. ${ }^{91}$ Rawls can argue that voters do need to hold themselves to this standard when he says that voters must act as if they were legislators when voting.

Rawls believes that his discussion on the content of public reason will give sufficient answer to Waldron's concerns. Rawls argues that public reason will not be fixed to one set of premises and go on unchanged. Various forms of political conceptions, fleshed out in the ways outlined above, can be admitted into public reason. Rawls specifically mentions the "Catholic views of the common good and solidarity" as compatible with public reason and as being parts of a political conception of justice, so long as "they are expressed in terms of political values." 92 Public officials can then behave in the ways that Waldron thinks they should be able to, so long as they translate their values into the public values. In most instances, this will not create problems. Waldron himself points out the ways in which the bishops' claims apply to shared political conceptions of justice. Rawls says: “Thus, Jeremy Waldron's criticism of political liberalism as not allowing new and changing conceptions of political justice is

89. Waldron, "Religious Contributions," 827.

90. Ibid., 829.

91. Ibid., 828-829.

92. Rawls, "Public Reason Revisited," 142. 
incorrect. ${ }^{993}$ Rawls then, however, tells us to look at Lawrence Solum's response to Waldron. ${ }^{94}$ I now look at this response as being in line with Rawls's thinking.

\section{3}

We have seen that Waldron's argument rests on the idea that Rawls wants us to reason from a set of shared premises, or some kind of other consensus. Solum breaks down Waldron's argument to show that Waldron is essentially saying that: "Rawls's ideal of public reason counts a reason as public if and only if that reason is (a) itself an existing premise that everybody already shares, or (b) it follows from an argument that has only existing premises that everybody already shares as premises." ${ }^{95}$ This is the first premise in Solum's breakdown of Waldron's argument, and the important one for our purposes, as Solum argues that this first premise is where Waldron goes wrong. Waldron, according to Solum, goes on to show that since public reason only allows reasoning from shared premises, no new premises will be permitted, and this is undesirable. ${ }^{96}$

I have attempted to show other aspects of Waldron's argument. Waldron spends a great deal of his article showing why nonpublic reasons can work without causing political gridlock, and Solum does not fully capture whether or not Waldron is successful. Restricting discussion to public reason is not necessary for Waldron because a deeper, more meaningful agreement can be reached through open debate. Waldron tries to show the potential for agreement through these debates with the application of the bishops'

93. Rawls, "Public Reason Revisited," 143, n. 30.

94. Ibid.

95. Lawrence B. Solum, “Novel Public Reasons,” Loyola of Los Angeles Law Review 29 (19951996): 1475.

96. Ibid., 1476. 
letter, and Rawls and Solum do not give us reason to disagree. Regardless, Waldron's ultimate point is that Rawls cannot allow for new ideas because his ideal of public reason is too narrow.

Solum makes five arguments against Waldron, but the first two in which he attacks what he believes Waldron got wrong about Rawls are what concern us here. Solum argues that Waldron fails to distinguish acceptance from availability, and "confuses universal agreement with wide agreement among reasonable persons. ${ }^{.97}$ Solum argues that universal agreement cannot be supported by any of Rawls's arguments, and that Waldron is reading in something that is not there. ${ }^{98}$ This second critique is then folded into the first one as wide agreement also means that something is widely available. ${ }^{99}$ Waldron does believe Rawls to be arguing for a system in which people must begin with shared premises, but Solum states that "a reason may be available to the public, even if it is not yet accepted by the public." ${ }^{100}$ This means that an argument need not already be accepted, but just be widely available. Availability means that an argument has the potential to be "widely accepted if it were considered by the public at large.", This means that the argument is in line with "constitutional essentials." ${ }^{102}$ Solum also notes that Rawls sometimes discusses the ideal of public reason as stemming from "preexisting agreement among citizens about the premises of political argument," but that "there is nothing in his underlying arguments that requires this restriction." ${ }^{103}$ This seems to derail Waldron's entire argument. Despite saying many times in his early work that

97. Solum, "Novel Public Reasons," 1476.

98. Ibid., 1478.

99. Ibid.

100. Ibid., 1477.

101. Ibid.

102. Ibid.

103. Ibid. 
public reason comes from some form of consensus, it would seem that public reason is defined by what could be accepted and not by what is accepted. This is in line with Rawls's discussion of the content of public reason. What exactly is meant by 'widely available' though, is not entirely clear. Rawls argues for the accessibility of public reasons in terms of political conceptions that are reasonable. This essentially means that they seek fairness by following the criterion of reciprocity, as well as have values that are in line with a democratic constitution. If political conceptions for Rawls lack basic values that are in line with constitutional democracies, then they cannot be reasonable. When Rawls discusses the benefits of presenting comprehensive doctrines in the public square, he does so in terms of the various citizens acknowledging a mutual allegiance to constitutional democracy in their doctrines. This amounts to the content of public reason being available through an overlapping consensus. Such a consensus amounts to various comprehensive doctrines coming to hold the foundations of justice in their society, to be justified by their comprehensive doctrines. This must be the starting point for Rawls because comprehensive doctrines must be minimally reasonable in this way or there would be no starting point. This is also part of "the liberal principle of legitimacy" as Solum points out that legitimacy means power is justified in light of "constitutional essentials that all citizens may reasonably be expected to endorse in light of principles and ideals acceptable to them as reasonable and rational." ${ }^{104}$ It is unclear if Waldron conceived of Rawls's consensus in terms of a minimal overlapping consensus, or if he believed that every premise of debate must be thought out and encoded in society in advance in the way Solum characterizes his argument. Either way, it is also unclear if this

104. Solum, "Novel Public Reasons," 1477. 
truly saves Rawls's public reason from the charge of being too narrow. After all, what does it truly mean for a reason to be given in terms anyone can accept, or for it to be widely available?

Solum gives a fairly detailed list of what counts as available to all citizens. That being said, his description of availability can lead you to wonder what will not count as available to the public. Solum states:

Prior acceptance is one route to availability, but it is not the only route. For example, a reason can be available to a given citizen because it fits with the citizen's other beliefs. Another route of availability would be deductive; a reason is available to a citizen if that reason follows from the citizen's other beliefs. A reason may be available if it is intuitively plausible and does not contradict any of the citizen's other firmly held beliefs. ... This list of possibilities is just the beginning, for we can surely imagine a host of other mechanisms by which a novel reason could become available. ${ }^{105}$

We have seen that Rawls does not think public reason is about going to each individual or group interest and debating them on their terms. Solum's statements can seem a little strange then, because he is arguing for essentially that. The list he gives us for ways that reasons can be made available to all involves them having the potential to be shared by the individual's own beliefs. It is not clear if Solum would have meant political conceptions of justice, or comprehensive doctrines, when he discusses beliefs in this context. In either case, it would seem that these beliefs held by citizens must have a fair amount in common if citizens are expected to give reasons that are available to all of them. If Solum means political conceptions, then it is much more in line with what Rawls discusses in "The Idea of Public Reason Revisited," as 'available' could simply mean in line with constitutional basics and the society's foundation of justice. 'Available' may just mean minimally reasonable in this sense, rather than meaning a product of tailoring justifications to comprehensive doctrines.

105. Solum, "Novel Public Reasons," 1477. 
Despite Rawls's endorsement of at least some aspects of Solum's response to Waldron, James Bohman and Henry Richardson give us good reasons for separating their views on what kind of reasons can be given in public reason. Bohman and Richardson argue that liberal authors relying on the idea of "reasons all can/could accept" is ultimately misguided because it is far too difficult to come up with definitions of what it means for something to be capable of acceptance. ${ }^{106}$ They argue that "if the notion of RACAs [reasons all can accept] is to do serious theoretical work, it must sort reasons into two classes: those that all can accept and those that not all can accept." ${ }^{\text {107 }}$ This may seem obvious when first articulated, but many theories fail to outline the potentially subtle, but necessary, differences. In Solum's account of what is widely available, it is very unclear what might be an unavailable reason, or rather one that could be accepted by all. Bohman and Richardson go on to say that theories which rely on RACAs interpret these kinds of reasons as either empirical or normative. ${ }^{108}$ The empirical account is weak as it means that "empirical possibility is all that matters in setting the limits of what people "can accept'. ${ }^{\prime 109}$ By this, they mean that if it is conceivably possible for anyone to expand their way of thinking to the point of accepting the reason, then the reason could be accepted and the empirical account becomes effectively meaningless when given all the things people could conceivably open their minds to. ${ }^{110}$ They argue that "on an empirical reading of 'could accept,' there are no reasons intelligibly accepted by one person that could not be accepted by any other, apart from those that would be caught by the

106. James Bohman and Henry S. Richardson, "Liberalism, Deliberative Democracy, and 'Reasons that All Can Accept'," The Journal of Political Philosophy 17, no. 3 (2009): 257.

107. Ibid.

108. Ibid.

109. Ibid., 258.

110. Ibid. 
independent standard of excluding falsehoods."111 The authors go on to make the case that the "normatively constrained interpretation of "could accept""112 is superior, but that in every instance of a normative constraint, it is not the idea of 'can accept' that is doing the job of sorting reasons from acceptable or not acceptable, "but rather by the relevant normative notion, such as consistency with the requirements of reasonableness." 113 They go on to argue that Rawls completely bypasses the idea of RACAs by making reference to what reasonable people could reasonably accept. ${ }^{114}$ "Rawls's principle of legitimacy ... effectively asks us to determine, more abstractly and in general, whether a given reason is consistent with the constitutive commitments of reasonableness, which are the same for each person." ${ }^{\prime 15}$ On this account, we can see Solum's approach as empirical in so far as the tests he gave for availability are to check if the conception of justice can be fit with someone's deeply-held beliefs.

Bohman and Richardson make a compelling case for why Rawls avoids the problems of other authors. They end up defending Rawls in a way that goes beyond what Solum does. Solum does not offer us any standards by which to judge reasons. This criteria for public reason does not require setting up any standard beyond the standards of reasonableness that Rawls always uses. A comprehensive doctrine that is reasonable should accept any reasonable premises. It is true that using the idea of what 'could be accepted' is a weak standard to judge things by, and judging the reasonableness of a political conception to some degree gives us an independent standard. Rawls can also be

111. Bohman and Richardson, "Liberalism," 258.

112. Ibid.

113. Ibid., 257.

114. Ibid., 259-260.

115. Ibid., 260. 
seen as simply pushing the problem farther down the line. Part of reasonableness in public reason means fairness and an expectation of reciprocity. We then run into the exact same problems as Solum when we try to create a standard for reasonableness, because it turns out that checking the reasonableness of a premise just checks to see if it is in line with basic constitutional democratic ideas. This is the same test as imagining if someone else could possibly accept the reason, because it only requires you to translate your reasons to political terms. I do not think Rawls completely escapes this idea of 'can accept' or realizes how flimsy a standard it is for what constitutes public reasons.

Through this treatment of Solum and Bohman and Richardson, it becomes the case that as long as it is suitably translated, almost anything can become a public reason in the appropriate sense. This certainly responds to Waldron and shows that Rawls's public reason is very inclusive of all ideas. It would seem to become more inclusive than even Rawls intended, as it is not controversial private reasons being excluded, but the manner in which they are brought to the political forum that is being changed. If this is the case, then what real work is translation doing? In what areas is it appropriate to have neutral language, and where is it unnecessary? The manner in which we discuss topics in the political forum matters almost as much as the content at times. Citizens who cannot speak with their own voice could become alienated from the political system, because they are not being heard in the way that matters to them. 


\section{4}

Christie Hartley and Lori Watson divide the arguments for an inclusive account of public reason into three types. ${ }^{116}$ These authors consider "an inclusive account of the idea of public reason" to be one that "permits comprehensive value claims as justifications for constitutional essentials and principles of basic justice; exclusive accounts prohibit individuals from appealing to comprehensive values in their justifications of these principles." 117 The three types of arguments are the nothing-to-lose, the something-togain, and the non-alienation arguments. ${ }^{118}$ The nothing-to-lose argument states that we have reason to believe that agreement can be reached with the inclusion of comprehensive conceptions of justice, we have no reason to believe that agreement could only be reached on political conceptions alone, and therefore inclusion of comprehensive doctrines does not destroy a chance at agreement. ${ }^{119}$ The something-to-gain argument essentially states that public debate on comprehensive doctrines will improve those comprehensive doctrines and also improve the lives of citizens. The argument says that agreement can be reached from this process, and therefore political debate that includes comprehensive doctrines produces superior public debates. ${ }^{120}$ We can actually see both of these arguments in Waldron. The response to Waldron in Rawls was to essentially claim that through public reason we can still gain everything we otherwise would, without risking any loss. Part of the reason Rawls says we still gain everything we otherwise would, is because the proviso still allows for the mention of comprehensive doctrines.

116. Christie Hartley and Lori Watson, "Feminism, Religion, and Shared Reasons: A Defense of Exclusive Public Reason," Law and Philosophy 28 (2009): 505-507.

117. Hartley and Watson, "Feminism," 502.

118. Ibid., 506-507.

119. Ibid., 505-506.

120. Ibid., 506. 
Citizens can learn about other viewpoints through these kinds of mentions, but there will still be strictly public reasons to allow for justification.

What Hartley and Watson term the non-alienation argument is concerned with alienation in two senses, although the argument has the same structure in each instance. The difference is in whether any given articulation of the non-alienation argument is concerned with the state alienating individuals from their own beliefs, or if they are concerned with individuals with strongly-held beliefs becoming alienated from the political forum. The structure of the argument as Hartley and Watson describe it is as follows:

a. Central to liberalism is the toleration of diverse religious beliefs and conceptions of the good more generally.

b. Moreover, the liberal state is thought to be consistent with, if not conducive to, religious citizens being able to participate in public, political life without feeling alienated from their religious beliefs or from politics.

c. Exclusive or stringent accounts of the idea of public reason will result in the alienation of persons from either their religious beliefs or the political process insofar as citizens will not be able to justify basic principles of justice and constitutional essentials on the basis of (some of) their most deeply held beliefs.

d. Therefore, we ought to adopt a more permissive account of the idea of public reason that allows citizens to appeal to their comprehensive doctrines in the exchange of public reasons provided that such appeals are also accompanied by arguments that appeal to shared political values. ${ }^{121}$

Hartley and Watson give this type of argument for an inclusive account of public reason a special place, and argue that it is the most compelling kind of argument for political liberalism. ${ }^{122}$ This is because the first premise of the argument is dealing with a liberal commitment of toleration. Nonetheless, they conclude that the fear of alienation cannot be sufficient reason to give comprehensive doctrines the ability to count as justifications. Solum, they argue, clearly gives comprehensive doctrines justificatory powers when he

121. Hartley and Watson, "Feminism," 509

122. Ibid. 
says they can serve as other or sufficient reasons. ${ }^{123}$ They assert that "for political liberals, justified or sufficient reasons are reasons that are, in principle, capable of being shared among those to whom they are to serve as a justification; they must be political." ${ }^{124}$ Hartley and Watson argue that Rawls's view of the idea of public reason is only possible within political liberalism if the proviso introduces comprehensive doctrines as explanations only, and never as justifications. ${ }^{125}$ The proviso does appear to operate in this way, but the distinction is not necessarily clear-cut. The intention of the speaker may not always be interpreted properly, and explanations could be taken as justifications. The distinction between explanations and justifications is also dubious. Explaining why you hold a certain justification to be most convincing is in essence justifying that justification, and you end up with comprehensive doctrines acting as justifications for your political beliefs.

Hartley and Watson cite an argument put forward by Paul Weithman which illustrates a compelling case of the non-alienation argument. Weithman argues that for liberalism to be acceptable it "cannot foster a culture of disbelief." ${ }^{126}$ By this Weithman means a situation where "religious organizations decline in membership and influence," "an increasing number of citizens accord religion a marginal role in their lives," or citizens "significantly misunderstand religion and its role in the lives of believers." 127 This conception of the argument brings us back to the question of to what degree a state should be allowed to change the values of its citizenry. Presumably, deliberative

123. Hartley and Watson, "Feminism," 510.

124. Ibid.

125. Ibid., 512.

126. Ibid., 507, n. 42.

127. Weithman, quoted in Hartley and Watson, "Feminism," 507, n. 42. 
democracy must change the values of their citizens to some degree, for that is the very project of deliberation. If a "culture of disbelief" comes about through just deliberation, is that deliberation then retroactively found to actually be unjust? State neutrality is certainly an important aspect in the sense that toleration demands we not impose certain beliefs on citizens. It is perhaps important to have some idea of how much it is reasonable for deliberation in deliberative democracies to change the comprehensive doctrines of its citizens. Rawls would argue that if we move from premises that can reasonably be expected to be seen as minimally reasonable, any result of deliberation is just. On this point, I am inclined to agree with Rawls just because it seems strange to put boundaries on how convincing deliberation can be in a democracy so long as the deliberation is done in a fair manner. I would add to the criteria of fairness and reasonableness, that the deliberation be done in a way that takes special care to appreciate the unique situation of the various contending views.

While Weithman's account of alienation raises a troubling case for public reason, Hartley and Watson then turn to what they call the truly "troubling case of alienation." 128 This case "occurs when citizens feel alienated or excluded from the political process itself - where good faith efforts to engage in the exchange of public reasons are dismissed as the ranting of an ideologue or when individuals are excluded or marginalized in the political process on the basis of their membership in a certain social group." 129 The authors do not offer a solution to this type of alienation, but simply cite it as the problem case because it relies on certain groups in society being seen as incapable

128. Hartley and Watson, "Feminism," 526.

129. Ibid. 
of being free and equal citizens. ${ }^{130}$ One thing worth noting, before moving to a discussion of this type of alienation, is that Hartley and Watson do argue that in a society in which one group is dominated in such a way that they are denied equal rights or equal legal standing, public reason cannot exist. They argue that liberalism and public reason apply to a well-ordered society, but in a situation where such a group is denied basic rights, liberalism is impossible. ${ }^{131}$ The most interesting element of this argument is that the example the authors use is that of Dr. Martin Luther King Jr.'s arguments in the civil rights movement, and the arguments made by abolitionists. Dr. King and the abolitionists made many Christian arguments for why their agendas should be furthered, but ultimately couched those reasons in public political discourse through a political conception of justice that focused on the basic rights of man. These arguments fulfill the content of public reason for Rawls, and are a success story for the proviso furthering the rights of a marginalized group without that group distancing themselves from their comprehensive doctrines. Rawls uses these examples as perfect uses of the proviso. ${ }^{132}$ Hartley and Watson, however, maintain that the arguments made by Dr. King and abolitionists do not fit into public reason, and fail the duty of civility. ${ }^{133}$ Ultimately, society was not sufficiently well-ordered for liberalism and public reason to be applied at all. This indicates a much stricter application of what it means to be a well-ordered society than Rawls. While Rawls never explicitly says which real societies are examples of his potentially idealistic well-ordered society, he gives American examples of when the duty of civility or proviso is fulfilled, and it is not unreasonable to suppose that Rawls

130. Hartley and Watson, "Feminism," 526.

131. Ibid., 522.

132. Rawls, "Public Reason Revisited," 154-155.

133. Hartley and Watson, "Feminism," 521. 
would find the U.S.A. at least somewhat well-ordered since it is a constitutional democracy of a certain type. On Hartley and Watson's strict account, any society that has politically alienated groups cannot be sufficiently liberal, and so anything and everything can be included in public debate. It is then unclear in what context they would see public reason being used.

Up to this point, Rawls has been able to respond to most of the critiques aimed at him. Waldron's concern for the exclusion of ideas is answered by the proviso, and the idea that almost all ideas can be translated. Anything that will not be perfectly translated can also be relegated to the background culture. Hartley and Watson illustrate that the most compelling case for public reason causing exclusion is when it leads to a form of political alienation. Arguments to avoid this kind of alienation are the most convincing because they begin with liberal premises and values similar to those that led us to public reason. A system of public deliberation which has the potential to lead to agreement should be concerned with avoiding alienation. Hartley's and Watson's solution of declaring a society not liberal enough for public reason to apply, will not work for Rawls. It would seem that unreasonable doctrines would necessarily be alienated from the state, because their inability to seek fair terms is mainly what makes them unreasonable for Rawls. It would seem, then, that Rawls thinks a society can be well-ordered but still possess alienated groups. Political alienation, in which groups or individuals feel unable to participate in a way that is valuable to them, would seem to be the kind of exclusion we need be concerned with. 


\section{5}

Sonia Sikka argues that Rawls believes that "religious reasons rest on metaphysical premises that are not fully intelligible, let alone acceptable, to all citizens, and that rules and policies enforceable by state power cannot rest on reasons of this sort in a liberal democratic society whose conception of justice is supposed to be neutral towards competing worldviews." 134 This will seem very familiar to us by now and a fair account of Rawls's view. What Sikka takes issue with is the idea that any religious doctrine needs to be translated into secular reasons because there is something especially uncivil about religious reasons. Sikka traces this sentiment to the idea that religious reasons necessarily include an appeal to authority as their underlying justification, and only an appeal to authority. ${ }^{135}$ She argues, taking the lead from a later work of Waldron's than we have examined, that religious reasons do not simply appeal to authorities, but rather individuals use religious authorities to inform and support their views in the same way secular reasons would use the work of an economist. ${ }^{136}$ Rawls does specify that public reasoning is not secular reasoning, because all of public reason denies admittance of comprehensive doctrines. Sikka argues that Rawls does require more of religious comprehensive doctrines because from the start they are less in line with political conceptions of justice that liberalism would accept, and thus require translation before being entered into the public political forum. Whether or not this is a fair accounting of Rawls is a difficult question. Certainly some comprehensive doctrines will be close to political conceptions that are more welcome in society than other comprehensive

134. Sonia Sikka, “On Translating Religious Reasons: Rawls, Habermas, and the Quest for a Neutral Public Sphere,” The Review of Politics 78 (2016): 96.

135. Ibid., 101.

136. Ibid. 
doctrines. If we take what Rawls says about reasonable comprehensive doctrines being a part of an overlapping consensus seriously, then I think most of this will become less problematic.

Sikka cites arguments from Simone Chambers and Maeve Cooke in saying that it is the manner in which religious reasons are proposed and whether or not they are "epistemologically authoritarian" $" 137$ that should determine whether or not religious reasons have a right to be included in public deliberation. I would argue that Rawls would accept this view, except he would also claim that any comprehensive doctrine is epistemologically authoritarian since it will rest on some premise that not everyone can be expected to accept. If a view is not epistemologically authoritarian, then it is able and willing to be defended in fair processes of argumentation. ${ }^{138}$ For Rawls, any view that is capable of being defended in these processes is simply a political conception of justice, and these processes would be public reason.

Sikka then discusses Rawls's commitment to limiting public reason to only constitutional essentials and matters of basic justice. For Sikka, the distinction between the background culture and the political public forum, as well as the proviso and an insistence on variety in political conceptions of justice, are not enough to allow us to ignore Waldron's novelty objection. ${ }^{139}$ Translation is not a solution here because she sees it as either unnecessary or harmful to the message. She argues that novel reasons, by which she means reasons typically barred from public reason, may be challenging the

137. Sikka, "Translating Religious Reasons," 102.

138. Ibid.

139. Ibid., 105. 
very foundations of justice and personhood that public reason limits itself to. ${ }^{140}$ Thus, arguing for a robust background culture is meaningless if the reasons cannot affect these issues. Sikka considers the view that this is a good thing because it saves us from theocracy or slavery, then asks "but what of arguments that bring to light culturally specific biases in the liberal conception of persons, in a way that challenges basic political principles but is not self-evidently morally odious?"141 As an example of this Sikka points to "an anthology called Spiritual Ecology: The Cry of the Earth." "142 The anthology includes several works that Sikka argues set up nature as being sacred, and posit that our relation to nature is fundamentally different than what is typically thought of as, or accepted by, common knowledge. ${ }^{143}$ This example points to comprehensive doctrines that supposedly cannot be put into liberal political conceptions of justice in compelling ways. Sikka wants to show that translation into political values is not always enough. In all likelihood, many spiritual beliefs about nature could become part of the basic structure of society through a translation that gives certain rights to nature. In Bolivia, they have "The Rights of Mother Nature" encoded in law. ${ }^{144}$ Whether or not nature is spiritual will not be discussed in the political realm, but the political values that can lead us to treat nature as spiritual can be debated. The ease of translation has helped Rawls avoid many critiques, but even with translation we can see how there can be alienation.

140. Sikka, "Translating Religious Reasons," 105-106.

141. Ibid., 106.

142. Ibid.

143. Ibid.

144 . Nick Buxton, “The Law of Mother Earth: Behind Bolivia's Historic Bill,” Global Alliance for the Rights of Nature, accessed July 15, 2016, http://therightsofnature.org/bolivia-law-of-mother-earth. 
Sikka discusses the second form of alienation, although she does not frame it in this way. Sikka states "there is a serious danger, moreover, in predominant paradigms coming to see themselves as 'rational' all the way down, or as metaphysically 'neutral,' out of a failure to recognize the thickness of their own bedrock assumptions." ${ }^{145}$ As an example of this danger in practice, Sikka references a Canadian documentary Water on the Table, despite acknowledging that the film exists in the background culture of society. ${ }^{146}$ In the film, two sides of a debate over water rights are portrayed; however, one side of the debate characterizes the opposing view as religious and therefore not worthy of acknowledgement. ${ }^{147}$ Sikka goes on to say that the view which stands opposed to the religious view of water does not recognize the "culturally specific and historically evolved, set of ideas about human beings, nature, and property." ${ }^{, 148}$ Furthermore, "through the deployment of a dichotomy between the religious and the rational ... the views placed on the religious side of the dichotomy are through this gesture deprived of authority." $" 149$ This is a very salient way of showing the real harm that can occur through too strict an adherence to Rawls's idea of public reason. It promotes a culture where some reasons are necessarily more reasonable than others before the content of those reasons is even examined. Even with the proviso, this has the potential to lead to alienation from not only political debates, but also from debates in the background culture. Rawls's idea of public reason can be seen as fostering a culture where the best reasons are those that are

145. Sikka, "Translating Religious Reasons," 110.

146. Ibid., 110-111, n. 83.

147. Ibid., 110.

148. Ibid.

149. Ibid. 
as free of metaphysical commitments as possible. This is not inherently negative, but if it alienates groups in society then it is undoubtedly doing harm.

The case of the Indigenous peoples of Canada renders this idea more concrete. First of all, I assume Rawls would consider Canada a society well-ordered enough that liberalism and the idea of public reason applies to at least some extent. Another potential problem is that Rawls says the political relationship as citizen can only be entered into by birth, but most Indigenous people in Canada entered into a political relationship with the rest of Canada through forceful assimilation and repeated attempts at the destruction of their comprehensive doctrines. The Canadian legal system has formed an idea of Indigenous rights to help combat this, but Matthew Tomm points out several ways in which a Rawlsian idea of public reason is still inhibiting Indigenous peoples' attempts at full participation.

To participate in the Canadian political or judicial framework, both areas that Rawls would outline as being the domain of public reason, Indigenous peoples must justify their rights in the terms of the culture that holds sway over them. Tomm writes: "Anglo-European concepts of justice are hegemonic in Canada - the fact of conceptual hegemony. And it compels Indigenous people to articulate their concerns within Western normative frameworks - the hegemonic constraint."150 This means that any participation in the public political forum is limited by the culture that has oppressed them. Despite gaining formal equality, the framework in which Indigenous peoples must reason is one to which they potentially lack access. Tomm actually acknowledges that Rawls's idea of public reason serves as protection from Aboriginal viewpoints being completely 
dominated by more dominant views. ${ }^{151}$ However, he also notes a common critique among Indigenous philosophers is that "when Aboriginal people complain of being constrained to the language of the majority, they are primarily referring to the language of liberalism." ${ }^{152}$ If Indigenous peoples' varied comprehensive doctrines cannot accept a constitutional democracy or the idea of reciprocity, then it would seem that Rawls would dismiss these doctrines as unreasonable and thus unsuited for inclusion in a well-ordered society. Yet it was this kind of attitude that led the Indigenous people to this situation. The decision, which Canadians have come to accept as erroneous, that Indigenous culture was not worthy of civil society is exactly what Canada is now trying to rectify. Rawls does not give us very useful tools to decide which comprehensive doctrines are unreasonable in "The Idea of Public Reason Revisited," and simply says that each society will have to figure it out for themselves in accordance with the principles of justice. ${ }^{153} \mathrm{He}$ does address this question in other places, but not with much more determinacy. Rawls asserts that unreasonable doctrines will deny reciprocity and will seek to have their version of the truth dominate political culture. ${ }^{154}$ Rawls goes on to note that the elimination of all unreasonable doctrines is impossible, despite unreasonable doctrines threatening democracy, and says that "this fact is not a defect or failure of the idea of public reason, but rather it indicates that there are limits to what public reason can accomplish. It does not diminish the great value and importance of attempting to realize that ideal to the fullest extent possible." ${ }^{, 155}$ Thus the desire to have their unique voices

151. Tomm, "Public Reason," 301.

152. Ibid.

153. Rawls, "Public Reason Revisited," 178-179.

154. Ibid.

155. Ibid., 179. 
heard in political discourse does not render the arguments from Indigenous comprehensive doctrines unreasonable, and Canadians have expressed the unreasonableness of eliminating Indigenous perspectives. If the only real criteria for unreasonable comprehensive doctrines is that they try to dominate others, then let us explore whether or not Indigenous comprehensive doctrines are unreasonable, and whether or not their desire to have their unique perspectives addressed in law can be satisfied by Rawls's proviso, or if it specifically demands something outside of Rawls's framework.

Tomm does not address Rawls's conception of the proviso. I shall explore a case study that Tomm discusses with the proviso and unreasonableness in mind. The case involves the Kitchenuhmaykoosib Inninuwug (KI) First Nation of Ontario filing an injunction against a mineral prospecting company, Platinex Inc.'s use of land. ${ }^{156}$ The case went through three stages. In the first trial, KI introduced a Treaty Land Entitlement Claim, which means that the Ontario government had to determine whether or not the KI had a claim to the land that they were trying to protect from mining operations. The judge ruled that harm would be done to KI if Platinex was allowed to begin drilling because KI might lose a valuable tract of land that is being resolved in their Title Claim. ${ }^{157} \mathrm{KI}$ also gave reasons stemming from their cultural and spiritual beliefs about the land, and how the loss would erode their beliefs through a failure to protect the land, which the judge said could not be ignored. ${ }^{158}$ In some sense this can be seen as KI giving a nonpublic reason as an explanation, but a corresponding political reason for the judge, thus fulfilling

156. Tomm, "Public Reason," 306.

157. Ibid., 307.

158. Ibid. 
the proviso. However, the reason that KI wanted to protect its culture can be a political reason in itself so long as the political conception entails a right to culture. None of this debate was framed in a way that discounted the views of KI, but they also presented reasons from their unique experience. The judge sided with KI and gave them a year-long injunction. When KI and Platinex could not reach agreement in that year, they went back to court and the issue was again about harm. ${ }^{159}$ In this round of debate, "Platinex argued that the potential harm of its drilling operations to the land was minimal ... [but] KI disagreed, claiming that from an Aboriginal perspective even 'minimal' alteration can be, and in this case was, very serious." ${ }^{160}$ What measures the court could use to measure harm then became the core issue. Here, KI introduced arguments based solely on their view of nature and the world, whereas Platinex based their arguments in more publicly accepted forms of reasoning. KI was still not necessarily presenting comprehensive doctrines to the court in a way that would be problematic with Rawls's idea of public reason. They were arguing that their culture deserved to be protected and then making the empirical claim that this harmed their culture. Unfortunately, that is a claim that is not easily tested, and while KI would seem to be stuck with making claims to the nature of their spiritual culture, Platinex can make scientific claims to what will actually happen to the land. In the end the judge ruled against KI. ${ }^{161}$

In the final aspect of this case, a group of KI members tried to stop Platinex from performing their operations, and, as a result, were charged with contempt of court. ${ }^{162}$ The actions of these band members would seem to be the first actions that KI took that were

159. Tomm, "Public Reason," 310.

160. Ibid., 310.

161. Ibid., 311 .

162. Ibid. 
unreasonable in the Rawlsian sense. They refused to accept the terms of reciprocity and seemed to expect others ultimately to conform to their private beliefs in regard to this piece of land, as their only justifications were from their comprehensive doctrines. Still, the unreasonable behaviour of some adherents of a comprehensive doctrine does not make that doctrine inherently unreasonable. The case study does show that Aboriginal comprehensive doctrines were somewhat capable of being presented through liberal political conceptions insofar as they presented their views of the world, and then argued from a system of rights for what these views meant. This could be seen as following the proviso. However, it is unclear if every situation in which Aboriginals wish for their unique experiences to be properly respected can be satisfied by expressing their comprehensive doctrines through the proviso. It is also worth noting that their description of harm was ultimately defeated by one more in line with liberal language.

Denying inoffensive comprehensive doctrines access to the public political forum as justifications does not seem immediately, or obviously, wrong. The problem with alienation is the most troublesome when applied to those on the fringe of society who are being marginalized by a limited capacity for participation. We can see this as stemming from a prevalent mindset which looks down on reasons that are put on the opposite side of what is reasonable. It is at least plausible for alienation in the background culture to affect political participation through a devaluing of viewpoints. Rawls demands translation as a way to make viewpoints admissible in public debate, and this leads to the fostering of a system that comes to value shared political principles above private beliefs. The problem is when groups do not share those political values, then translation may not be enough to participate fully, and their own beliefs may be devalued. 


\section{6}

The last critique to be considered is the feminist one originally put forward by Susan Moller Okin. Okin argues that the distinction between the public and private spheres of life (political forum and background culture), is indefensible. Rawls holds that you can have a political conception that must necessarily view citizens as free and equal, but at home have a hierarchical view of justice and gender justified by religion. ${ }^{163}$ Okin is attacking the possibility of an overlapping consensus between certain religious views and liberal political conceptions, and argues that Rawls makes too much room for religion in his attempts to tolerate groups in society that hold power and are numerous. Okin asks us to consider the case of a girl and a boy raised together in a house exhibiting traditionalist gender norms, and who attend a religious school. ${ }^{164}$ If the boy and girl are being taught completely different ways of life, and are never exposed to anything else, Okin argues that there is no sense in which both children are becoming "free and equal citizens." ${ }^{\prime 65}$ Okin thinks that the way Rawls leaves families out of the basic structure of society leaves children and women open to this kind of oppression. The strongest position Okin sees Rawls taking, on unreasonable comprehensive doctrines, is that "the principles of any reasonable political conception must impose restrictions on permissible comprehensive views, and the basic institutions those principles require inevitably encourage some ways of life and discourage others, or even exclude them altogether."166 This interpretation of Rawls ultimately amounts to denying comprehensive doctrines that deny reciprocity and is in line with our discussion of unreasonable comprehensive

163. Susan Moller Okin, "Political Liberalism, Justice and Gender," Ethics 105, no. 1 (1994): 29. 164. Okin, "Political Liberalism," 29.

165. Ibid.

166. Ibid., 30. 
doctrines above. Okin wants to make Rawls admit that the family must be included in the basic structure of society, and is thus a matter of justice which can then allow her to keep what she sees as unreasonable, comprehensive doctrines from harming the substantive equality of women. She argues that "surely the circumscription of women's roles in life, their segregation in religious life, and their exclusion from important religious functions and positions of leadership ... render them unreasonable by Rawls's own criteria." ${ }^{167}$ Okin goes on to argue that Rawls does not give us a good enough account of moral psychology and how the just citizen is developed. By 'just citizen’ here, I mean what Okin describes, namely the development of a citizen into one who seeks fairness/reasonableness. If families are meant to be schools of justice for Rawls, then it is impossible that they remain in the background culture of society, because there needs to be a public mechanism to ensure that children become free and equal citizens. ${ }^{168}$ Okin goes on to list many studies that show how a young girl's development can be negatively impacted by families that do not exemplify the kind of justice necessary to teach girls to be truly free and equal. ${ }^{169}$ She states that Rawls, "by separating out the sphere of the political, to which justice is to apply, from the personal, associational, and familial, within which there is to be great tolerance for many different beliefs and modes of life, he seems to close off the possibility of ensuring that families (and associations) are just." ${ }^{\prime 10}$

This is no small problem for Rawls. If Okin is right, then Rawls is being too inclusive. Not for the reasons we have seen though; rather, he is giving too much room to comprehensive doctrines that would potentially deny or hinder gender equality, and also

167. Okin, "Political Liberalism," 31.

168. Ibid., 35 .

169. Ibid., 35-37.

170. Ibid., 38-39. 
potentially cutting out feminist arguments from the debate unless they are framed as wholly political conceptions on matters of basic justice. Thus, unless the family is included in the basic structure of society, and is rendered susceptible to public reason critiques from feminists, the distinction between the public political forum and the background culture could potentially shield unreasonable doctrines.

One passage in "The Idea of Public Reason Revisited" seems entirely aimed at answering Okin's critique. Rawls says that he will use a political conception in line with public reason to assign a role to the family. ${ }^{171}$ He goes on to say candidly that family is part of the basic structure of society, because "political society is always regarded as a scheme of social cooperation over time indefinitely." 172 The family is then the unit by which Rawls see society as being perpetuated, and so can be debated using public reason. He goes on to say:

\footnotetext{
Thus, reproductive labor is socially necessary labor. Accepting this, a central role of the family is to arrange in a reasonable and effective way the raising of and caring for children, ensuring their moral development and education into the wider culture. Citizens must have a sense of justice and the political virtues that support political and social institutions. The family must ensure the nurturing and development of such citizens in appropriate numbers to maintain an enduring society.
}

Here, Rawls is very clearly outlining how and why the family is an important element of the basic structure of society, and therefore a subject of political conceptions of justice. However, Rawls goes on to specify that the principles of justice only apply to the institution of the family in the way that it is set up, and insofar as it needs to ensure fair treatment of the members of the institution. ${ }^{173}$ This way, Rawls argues that the "internal

171. Rawls, "Public Reason Revisited," 157.

172. Ibid.

173. Ibid., 158-159. 
life of families" does not have justice applied to them directly. ${ }^{174}$ Rawls makes the analogy with the church and argues that church governance does not need to be democratic, but apostasy cannot be a crime. ${ }^{175}$ Essentially, justice does not affect the inner workings of various institutions but always protects the members. This way, families do not have to follow principles of distributive justice, but members are always guaranteed equality and freedom. ${ }^{176}$ Lastly, Rawls argues that a domain or sphere of life can never be separate from justice. He states "if the so-called private sphere is alleged to be a space exempt from justice, then there is no such thing." ${ }^{177}$ Rawls's response to Okin appears to be fairly strong. He adds a bit more detail to what constitutes the background culture by assigning a more involved idea of the basic structure of society, and explains how the background culture still has matters of justice applied to it insofar as it protects citizens' freedom and equality.

An integral aspect of Rawls's position is missing, according to Okin. While Rawls puts the onus of teaching and raising children, as well as developing their sense of justice, with families, he does not give a robust account of how this moral psychology develops. Okin argues that Rawls needs this, or else families cannot be sufficient schools of justice. Rawls applies justice to families in certain ways, but mostly he just shows the potential for certain political conceptions allowing for debate on families. Rawls still leaves the internal life of the family alone, except for a guarantee that citizens' freedom and equality will be protected. This leaves it open for girls to be raised in ways that limit their freedom and equality in non-obvious ways, or even ways that are acceptable under this kind of

174. Rawls, "Public Reason Revisited," 158.

175. Ibid., 159.

176. Ibid., 159-160.

177. Ibid., 161. 
liberalism. Okin's core critique remains at least somewhat intact. Nonetheless, it is unclear if a strong response from Rawls is desirable. Earlier, we were concerned with the degree to which the state in a deliberative democracy can influence someone's comprehensive doctrines. It would seem to be far too much interference for a liberal democratic state to impose strict guidelines on the raising of children; guidelines that go beyond cases of welfare and seek to extract them from comprehensive doctrines in their home lives that the state sees as unreasonable at any given time. Once again we are reminded of Aboriginal peoples in Canada and the case of assimilation through residential schools. The degree to which Okin wants justice to apply to families is unclear, although at a basic level she wants a way to debate unreasonable comprehensive doctrines that limit gender equality. Rawls has perhaps provided at least that in his framework.

Rawls is able to respond to critiques about the exclusion of ideas by showing how many ideas or concepts can be readily translated into political values. As an integral aspect for Rawls's method of creating moral allegiance to the state, public reason fails by fostering a hierarchy of values and resentment in groups that lack shared political values. Okin asks for a clearer understanding in Rawls of what role the state plays in fostering the moral psychology of the individual. Rawls believes that members of a liberal society will have a certain moral psychology that is conducive to fairness, which aids in creating moral allegiance to the state, but what the values are that the state must instill in citizens for the public reason project to begin, is not immediately clear. Through this examination of public reason, we can see that the potential problems with Rawls's overlapping consensus are really problems with the limiting aspects of public reason. 


\section{$3 \quad$ Avoiding Exclusion}

The difficulty in assessing the problems with Rawls's account of an overlapping consensus is the closeness with which it is tied to his account of public reason. An overlapping consensus is Rawls's answer to social integration and cohesion in a democratic state that will naturally encourage pluralism. A close look at this idea, independent of the strict system of public reason created by Rawls, can show that many of the problems truly lie with Rawls's account of public reason and the importance he gives to the way in which the duty of civility will lead to an overlapping consensus. Charles Taylor's examination of secularism gives us useful conceptual tools for disentangling these concepts. The problems of alienating groups within society, as well as compromising state neutrality with a state moral psychology that can perpetuate the systems which create that neutrality, are not inherent to Rawls's idea of an overlapping consensus. In the end, we must see Rawls's account of public reason as a useful guideline for most situations and not as a road map to overlapping consensus. Finding terms that we hope everyone can understand will potentially help lead us to mutual understanding.

Rawls's overlapping consensus was not intended to be about secularism or state neutrality in the strictest of senses. In his early writings on an overlapping consensus, he wanted to make sure to show how it affected any comprehensive doctrine, and not just religion. This is key because most of the issues raised thus far have been critiques coming from religious groups in society. An overlapping consensus is comprised of those political conceptions of justice which all comprehensive doctrines can find allegiance to, which means that it is at least potentially independent of wider moral concerns. Rather, it 
only applies to "political, social and economic institutions." ${ }^{\text {"178 }}$ Rawls specifically mentions philosophical comprehensive doctrines to show how these are too general. ${ }^{179}$ This is significant to remember in the light of critiques on Rawls's conception of public reason because many of these critiques believe that public reason seeks a level of generality that is not possible or practical. Rawls wants political conceptions of justice to be very narrow in their application, yet to appeal to the political intuitions of a large number of groups in society. His fear is that if a political conception of justice is directly derived from any single comprehensive doctrine, it will be rejected outright by other groups. Rawls is not concerned with every group, as he does state that he wants "a consensus in which it is affirmed by the opposing religious, philosophical and moral doctrines likely to thrive over generations in a more or less just constitutional democracy." ${ }^{, 180}$ Which cultural groups meet this criterion is not clear, but the idea that only those aspects of society likely to persist over generations is Rawls's primary concern of stability. Rawls is looking for "a shared public basis for the justification of political and social institutions." ${ }^{, 181}$ An overlapping consensus can then be seen as the shared reasons to which everyone in society can make reference in the domain of public reason. Every citizen following the ideal of public reason, and their duty of civility in a constitutional democracy, will create an overlapping consensus by filtering out the reasons that are not shared, and finding the political values that overlap with all major comprehensive doctrines in that society. It is possible on this account that a society will find agreement on doctrines that go beyond the political, but in a liberal society, and

178. Rawls, "Overlapping Consensus," 3.

179. Ibid., 3-4.

180. Ibid., 1.

181. Ibid. 
given the fact of pluralism, Rawls sees this as unlikely. It remains a possibility because of the way Rawls's overlapping consensus begins with some form of more basic consensus. People in society need to develop similar intuitions on matters that allow for cooperation first and foremost. It is at least very likely that consensus will begin with political values, because these are the values that will allow for cooperation and the establishing of shared rules and reasons. In this way, Rawls's overlapping consensus is built up and then continuously reinforced by the idea of public reason.

Is this the only, or even the best, way that a society can reach an overlapping consensus? Public reason, conceived as a moral duty to impose a strict neutrality on any public official, or even anyone speaking in many public contexts, would seem likely to create discord among some groups in society. Rawls's goals are political community and, perhaps more importantly, institutional stability. A strict adherence to the kinds of ideals espoused by the ideal of public reason may be counterproductive to these main goals. Rawls thinks that an overlapping consensus in society will emerge from the various major comprehensive doctrines communicating and learning to trust each other.

Charles Taylor argues that Rawls, by seeking some level of reasoning that will eventually appeal to everyone and find some form of correctness, is sticking to outdated ideas left over from the enlightenment. ${ }^{182}$ Taylor argues that the enlightenment is conceived as stepping away from religion and into the realm of reason. He argues that Rawls would:

seem to reserve a special status for nonreligiously informed Reason (let's call this 'reason alone'), as though a. the latter were able to resolve certain moral-political issues in a way

182. Charles Taylor, "Why We Need a Radical Redefinition of Secularism," in The Power of Religion in the Public Sphere, ed. Eduardo Mendieta and Jonathan VanAntwerpen (New York: Columbia University Press, 2011), 52-53. 
that can legitimately satisfy any honest, unconfused thinker and b. where religiously based conclusions will always be dubious and in the end only convincing to people who have already accepted the dogmas in question. ${ }^{183}$

Taylor goes on to say "that this distinction in rational credibility between religious and nonreligious discourse, supposed by $a+b$, seems to me utterly without foundation." ${ }^{184}$ The idea is that reason independent of previous commitments can lead to firm, unshakeable truths which in turn lead to widespread agreement on moral-political beliefs. For Taylor, whether or not God is an illusion is unimportant because God still offers a valid starting point for the moral-political conclusions that follow. ${ }^{185}$ Some premises from this world will fulfill the requirement Taylor sets out in ' $a$ ', and these premises will appear as immediately and obviously true to us. They "should legitimately be convincing to any honest, unconfused thinker." ${ }^{\text {186 }}$ Certain mathematical and natural scientific truths can fulfill this requirement, but Taylor contends that no moral-political conception will. ${ }^{187}$ An interesting aspect to this is that Taylor uses utilitarianism and Kantianism to show how these comprehensive doctrines cannot have a truer basis for moral-political conclusions than any religious basis. ${ }^{188}$ These are the same examples Rawls uses to show how any comprehensive doctrine that is too general (that is, applies to situations outside the political) cannot form a true political conception of justice. ${ }^{189}$ Comprehensive doctrines of any kind will start with premises that cannot be accepted by many groups in society. They will not be immediately true to us as Taylor describes it. Taylor and Rawls seem to be making the same point, and yet Taylor charges Rawls with adherence to the $\mathrm{a}+\mathrm{b}$ myth

183. Taylor, "Redefinition of Secularism," 53.

184. Ibid.

185. Ibid., 53-54.

186. Ibid., 54.

187. Ibid.

188. Ibid.

189. Rawls, "Overlapping Consensus," 6. 
that comes out of the enlightenment. This highlights an important difference between the approaches of the two thinkers. As we have discussed, Taylor believes that an overlapping consensus is the only way to deal with pluralism in a democratic society. However, where Rawls thinks that we can reach a purely political conception of justice through reason alone, Taylor thinks an overlapping consensus will come from continuous discussions between a variety of moral-political outlooks. It is not a system with an end point for Taylor, where the best political values for cooperation are found through reasoning about them. When Taylor discusses moral-political conclusions, he is not making the same kind of distinction as Rawls, because he is trying to show the fruitlessness of that distinction. By moral-political conclusions, I take Taylor to mean any comprehensive doctrine which applies its moral starting beliefs to a political context. It would seem, then, that Taylor's primary concern is with Rawls's idea that we need (or can even have) a political conception of justice independent of comprehensive doctrines to act as a neutral basis for justification. The political conception needs the potential for neutrality for Rawls, so that one group is not dominating others.

Secularism for Taylor cannot simply be defined as an absence of religion in state institutions. Taylor argues that the commitment to secularism in democratic states is actually a commitment to three separate, but related, values that he distinguishes using "the three categories of the French Revolutionary trinity: liberty, equality, fraternity.", 190 The idea of secularism has been harmed by strict adherence to the separation of church and state. In many instances secularism, or really a more general state neutrality, requires compromises between these three values. Sticking to a single, supposedly timeless

190. Taylor, "Redefinition of Secularism," 34. 
principle that should lead to secularism in any context simply leads to the violation of one or more of these three values or goods. ${ }^{191}$ Taylor clarifies the three values in the following terms:

1. No one must be forced in the domain of religion or basic belief. This is what is often defined as religious liberty, including of course, the freedom not to believe. ... 2. There must be equality between people of different faiths or basic belief; no religious outlook or (religious or areligious) Weltanschauung can enjoy a privileged status, let alone be adopted as the official view of the state. Then 3 . All spiritual families must be heard, included in the ongoing process of determining what the society is about (its political identity), and how it is going to realize these goals (the exact regime of rights and privileges). This (stretching the point a little) is what corresponds to "fraternity." 192

Taylor goes on to accept that these goals can conflict, and suggests a potential fourth goal or value that he is tempted to link to fraternity. The fourth goal is "that we try as much as possible to maintain relations of harmony and comity between the supporters of different religions and Weltanschauungen." 193 These goals form a much better idea of what secularism is intended to accomplish. Conceiving of ways in which we can compromise on these goals, and maximize the values they encapsulate, takes us much farther in creating any kind of overlapping consensus than does Rawls's idea of public reason.

Taylor is concerned with eliminating a more common view of secularism, and one I do not think Rawls holds. The "wrong model" that Taylor thinks is disrupting our ability to attend to many issues surrounding secularism is that "we think that secularism has to do with the relation of the state and religion; whereas in fact it has to do with the (correct) response of the democratic state to diversity." ${ }^{194}$ Rawls is as concerned with diversity as Taylor is and, as I have said many times, does not want to reduce the problem

191. Taylor, "Redefinition of Secularism," 35.

192. Ibid.

193. Ibid.

194. Ibid., 36. 
to one that only applies to religion. Furthermore, Taylor applauds Rawls's overlapping consensus as holding to his new approach to secularism. When Taylor discusses the "lateRawlsian formulation for a secular state," he describes the state as supporting certain fundamental values that form the bases for the state, while allowing for many different "basic outlooks" to support these values. ${ }^{195}$ In this way, Rawls and Taylor have a common commitment to overlapping consensus, but we can distinguish what their very different commitments ultimately amount to.

Both authors are concerned with unity, but while Rawls frames it as the search for justification of the coercive actions of the state, Taylor discusses the formation of a common will. In certain ways, their discussions of the issue sound similar. Taylor is adamant that a state needs a voice and says that "for the people to be sovereign, it needs to form an entity and have a personality." ${ }^{196}$ In order for people to "act together ... to deliberate in order to form a common will on which they will act, requires a high degree of common commitment, a sense of common identification." 197 Taylor sees the modern state as asking questions that past states never had to, namely what or whom the state is for, and conceives of the emerging political identity "as the generally accepted answer to the 'what/whom for?' question." ${ }^{, 198}$ This process, through which democracies must define their collective identity, is "difficult and never-to-be-completed," but "constantly renewed mutual commitment," is necessary for the high level of mutual trust which citizens must create in order to live together and share in an overlapping consensus. ${ }^{199}$ In

195. Taylor, "Redefinition of Secularism," 37.

196. Ibid., 43.

197. Ibid.

198. Ibid., 44.

199. Ibid., 45. 
other words, we need to reach a level of fraternity through discussion. In the past, this was done by force or by a shared identity in state-mandated religion. Taylor argues that democracies of today are organized around "a strong 'philosophy of civility,' enshrining the three norms ... 1. Human rights, 2. Equality and nondiscrimination, and 3.Democracy." ${ }^{200}$ These are the bases for a democratic state that lead us to desiring the three goals of secularism and finding an overlapping consensus that can forge a stable political identity from these goals. Taylor does not make light of the difficulty in accomplishing this task, and the suspicion with which people holding different, basic views approach each other. He says that "the overlapping consensus between different founding views on a common philosophy of civility is something quite new in history and relatively untried. It is consequently hazardous."201 There is no way around it for Taylor, though, as a diverse democracy cannot return to the kind of civil religion before "without betraying its own principles," and as such "we are condemned to live an overlapping consensus. ${ }^{202}$

Rawls has society arrive at an overlapping consensus from consensus. There will already be a shared appreciation for certain intuitions that lead to political values. From these intuitions citizens can create the fair terms of cooperation that form the basic structure of society. In contrast, the only thing Taylor seems to need is mutual trust. Taylor's consensus comes from varied starting points that converge on an agreement, but they all begin with a capability for trust. For Rawls, this kind of trust will only emerge from shared political intuitions. An overlapping consensus for Rawls supports political

200. Taylor, "Redefinition of Secularism," 47.

201. Ibid., 48.

202. Ibid. 
values and the basic structure of society by linking those commitments to the prior commitment of their comprehensive doctrine, so long as those political values were already an aspect of said comprehensive doctrines. Convergence brings a variety of moral-political outlooks together to agree upon political conclusions. The only consensus that Taylor needs to begin with, is an agreement on mutual trust and a desire for mutual understanding between the parties involved. Valuing mutual understanding through discussion can bring about a more robust trust that others' views reliably match up with yours in certain ways. This trust creates the kind of reliabilism which Rawls gets through observing shared intuitions over time.

In Taylor's view, an overlapping consensus helps form a common will. However, Taylor goes on to say that "a society of this kind presupposes trust, the basic trust that members and constituent groups have to have, the confidence that they are really part of the process, that they will be listened to and their views taken account of by others." Here is where I see Taylor departing from Rawls. Taylor clearly believes that an overlapping consensus is the best answer to forming a legitimate common will in a democracy, but Taylor's commitment to fraternity goes beyond the idea of public reason that Rawls expects us to use in the creation and upkeep of such a consensus. The claim that the Indigenous people of Canada feel alienated from the political landscape when they are unable to communicate arguments from the culture in which they are embedded, can then be seen as a loss of mutual trust by denying an aspect of our fraternity goal. Through Taylor we can better understand what feels wrong about Rawls's idea of public reason. Forming an overlapping consensus is very important, but for Taylor it is about

203. Taylor, "Redefinition of Secularism," 43. 
creating trust in each other's viewpoints rather than about a belief in abstraction from those viewpoints leading us to consensus. Taylor calls the belief in one "master formula" which amounts to a set of unchanging institutional arrangements "a fetishization of the favoured institutional arrangements. $" 204$

I would argue that insofar as the duty of civility gives us one method of finding that shared trust by committing us to abstraction, and in the way that Rawls is committed to only forming the basic institutions of society through his overlapping consensus, Rawls is ultimately creating his own kind of master formula that breaks down in the way described by Taylor. Almost all of the critiques made against the idea of public reason that cannot truly be answered by Rawls's proviso, can be explained by Rawls's emphasis on the value of equality above and beyond the value of fraternity. Strict equality in terms of everyone communicating in reference only to what is shared cannot create trust. The proviso shows citizens that there are differences, but turning those differences into a common viewpoint does not give other groups any reason to find actual trust in your viewpoint, because mutual understanding has not been reached when both parties are seeking only a neutral and common justification. Translating our differences is not an adequate route to seeing other groups in society as reliably rational. Public debate needs to include these differences to create lasting trust, rather than fostering a sense that justifications that have not been translated into neutral speech are less worthy of consideration. If translation is occurring, then the original formulation already has the potential to be conceived of in political terms. Putting the onus on the speaker to speak in a certain way, rather than on the listener to seek greater understanding does not make

204. Taylor, "Redefinition of Secularism," 41. 
sense as a strict rule for creating an inclusive state where everyone contributes to the political identity.

The fixation on religion in the context of debates on state neutrality is also a huge problem for Taylor. He argues that this comes from the history of religious domination in Western countries, and that our institutions were built as a reaction to this history. Thus there is a strong focus on not allowing us to go back to this domination. ${ }^{205}$ Taylor warns of the risk that comes with never updating our institutions and says, "we risk needlessly limiting the religious freedom of immigrant minorities, on the strength of our historic institutional arrangements, while sending a message to these same minorities that they by no means enjoy equal status with the long-established mainstream." ${ }^{206}$ If an overlapping consensus is simply a method by which minority viewpoints are assimilated to the majority through long-standing and unchanging institutions (or basic structures), then it is exclusionary in a way that harms newcomers to the society and it eliminates diversity in a way that is antagonistic to the norms of democracy. But we can now see this as a result of a strict following of Rawls's public reason, rather than as an aspect of any overlapping consensus.

Taylor directly targets Rawls’s idea of public reason and calls it “tyrannical.,"207 Rawls's public reason in Taylor's description is a demand that we all communicate in the language of reason alone. Taylor sees the idea as a depiction of secular reasoning as something everyone can understand, and religious reasoning as something foreign to

205. Taylor, "Redefinition of Secularism," 48.

206. Ibid.

207. Ibid., 49. 
anyone not already a part of that religion. ${ }^{208}$ The idea that we need to communicate in a separate way that everyone can agree to, amounts to an epistemic distinction which places religious reasons as separate and unconvincing to the majority of people. The distinction makes it so that "religious reason either comes to the same conclusions as secular reason, but then it is superfluous, or it comes to contrary conclusions. And then it is dangerous and disruptive. ${ }^{, 209}$ Rawls renders religious reasons less rational. ${ }^{210} \mathrm{We}$ have already discussed the ways in which Taylor thinks this distinction and relying on some form of higher reasoning for moral-political issues, is untenable. Emphasizing the ways in which Taylor takes Rawls's idea of public reason to relegate religious reasons to a less rational standing is important in light of the discussion on alienation and fraternity. Despite Rawls's efforts to place public reason, and political conceptions of justice, as applying to no specific comprehensive doctrine, the reality is that the overlapping consensus of any state will be made up of political elements that are more heavily influenced by majority groups than by other groups. This is simply an unavoidable aspect of how both Rawls and Taylor conceive of an overlapping consensus. The larger groups will be able to have greater influence, and over time a certain degree of assimilation will be unavoidable. In Rawls's account, assimilation of that kind is desirable. The agreedupon bases for justification that public reason then draws from in Rawls's system will be built upon the least offensive elements of majority comprehensive doctrines. He simply argues that citizens have a duty of civility to demand neutrality to avoid irresolvable debates dominating the public sphere.

208. Taylor, "Redefinition of Secularism," 49.

209. Ibid.

210. Ibid., 51. 
It is worth noting that Taylor thinks Rawls is right to demand neutral language from the state in certain contexts. ${ }^{211}$ "The language in which legislation, administrative decrees, and court judgments," all must use a neutral language so as to avoid justification flat out falling to comprehensive doctrines. ${ }^{212}$ This list of neutral areas seems similar to Rawls's account of where the idea of public reason should be enforced, but Rawls's account is actually much larger in scope. Through the duty of civility, Rawls wants every citizen to make politicians and government representatives of any kind adhere to public reason in every context of public debate, or even public speaking. Taylor only wants the official decisions and decrees of the state to strive for neutrality. Legislation emerging from parliament must be phrased in neutral terms, but politicians on the floor of parliament need not translate their reasons into purely public ones the way Rawls would expect.

The question can then become at what level justifications need to be translated. Rawls and Taylor are both seeking a moral allegiance to the state. What differs is where it is necessary for translation to occur. Phil Ryan argues that Rawls's public reason is much less strict than I have described. He argues that there is elasticity in the idea of public reason, and that it is untenable to say it applies to all issues involving state power. ${ }^{213}$ To begin a project of public reason, Ryan argues that "we require a rich culture of deliberation" as this is what allows us to fully comprehend our own comprehensive doctrines and those of others. ${ }^{214}$ This requirement is part of what Ryan called the

211. Taylor, "Redefinition of Secularism," 50.

212. Ibid.

213. Phil Ryan, "Stout, Rawls, and the Idea of Public Reason," Journal of Religious Ethics 42, no. 3 (2014): 549.

214. Ryan, "Stout," 551. 
"culture-dependent aspect to the IPR[idea of public reason]." 215 The degree to which translation into general terms is necessary, for Ryan, is then determined by the attitudes of the citizens in any specific society. Ryan cites several examples in which religious statements, and even religious justifications, are harmless or useful in public debate, if the culture is such that the reasons will not be taken as hegemonic. ${ }^{216}$ In the end Ryan argues that "a widely embraced IPR could, over time, create a culture in which the IPR itself need only live on in a greatly relaxed form." ${ }^{, 217}$ I have been arguing that the best way to get to an open culture such as this, fueled by moral psychology that values mutual understanding in pluralism, is to begin with a relaxed form of public reason. Following public reason cannot be more important than encouraging the values that are meant to be expressed in secularism. Neutral state language is still important to stop majority viewpoints from becoming dominant and infringing on freedom. If we expect translation to be a duty that goes beyond those with power speaking in official or formal contexts, then we harm our ability to foster understanding. The duty of civility must only apply in these very narrow contexts.

With the help of Taylor, we can see a version of the overlapping consensus free of many of the complaints that previously faced it. When separated from a strict obedience to public reason, it is no longer exclusionary. A focus on secularism as a response to diversity, and the formation of an overlapping consensus in terms of ongoing compromises between liberty, equality, and fraternity negates concerns about alienation and cultural imperialism because it puts an emphasis on mutual trust and understanding.

215. Ryan, "Stout," 559.

216. Ibid.

217. Ibid. 
Instances where something is lost by trying to communicate ideas in purely public ways are not an issue because encouraging that kind of communication is a positive in this system. Rawls spends time showing how seemingly religious debates like those surrounding abortion can be reduced to human rights claims which can fall under the shared bases of justification. The proviso is meant to keep anything from being lost when this kind of reduction occurs by allowing mention of the comprehensive doctrine that informs the decision. As we have seen, though, something can still be lost when people must relegate their beliefs to the background. There is no good reason to think that strict neutrality in the public sphere will create social unity or stability in a way that is superior to public debate which strives for a discussion of differences. Deadlocks are perhaps inevitable, but focusing on mutual understanding and giving every viewpoint the right to be heard, allows for the fostering of a respect for diversity in a way that independently trying for universal justifications cannot.

A potential problem even for this revised idea of an overlapping consensus lies in the Okin critique. There still needs to be a robust aspect of the state that manages to shape the moral psychology of citizens in a way that allows for respectful diversity while also avoiding the entrenchment and perpetuation of harmful values in the family. The state must promote those values which allow the state to exist. Rawls's assumptions on human psychology give us some response to this. In general, Rawls believes that if basic institutions are formed correctly, they will foster a continuous moral character in the citizenry from one generation to the next. These institutions will foster "cooperative virtues of political life," such as "the virtue of reasonableness and a sense of fairness," 
which Rawls also believes will lead to mutual respect and a willingness to cooperate. ${ }^{218}$ Rawls says that "political liberalism tests principles and orders institutions with an eye to their influence on the moral quality of public life," but exactly what this means is unclear. ${ }^{219}$ Rawls uses 'moral' to mean normative, and in this instance he seems to be confining his statement to the public sphere. That being said, Rawls assumes a moral psychology in which humans essentially seek fairness. He says, "first, there are the assumptions contained in what I shall call a reasonable moral psychology, that is, a psychology of human beings as capable of being reasonable and engaging in fair social cooperation. ${ }^{, 220}$ He goes on to specify that these assumptions include the ability to form a conception of the good, a willingness to do their fair share when society is formed in a way they believe to be just, a tendency to develop trust in others who show this willingness, and that this trust deepens over time. ${ }^{221}$ Thus Rawls expects the state, at least in some way, to promote this moral psychology. He expects state institutions to teach us basic virtues of reasonableness and fairness, and then says that he assumes people with these traits will work together effectively to create stability. This is how the institutions of society support themselves. Elsewhere, Rawls writes that "the idea is that given certain assumptions specifying a reasonable human psychology and the normal conditions of human life, those who grow up under basic institutions that are just - institutions that justice as fairness itself enjoins - acquire a reasoned and informed allegiance to those institutions sufficient to render the institutions stable."222 This would seem to be the

218. Rawls, "Overlapping Consensus," 21.

219. Ibid.

220. Ibid., 22.

221. Ibid.

222. Rawls, "Domain of the Political," 246. 
extent of what Rawls gives in terms of an outline of how the state encourages a robust moral psychology. Essentially as long as society continues to operate under fair terms, then fairness will become an ingrained value. Yet this does not seem to adequately respond to Okin's concerns from the previous chapter. Okin did not think the family was a sufficient teacher of justice. Rawls believes the state will teach fairness, but that that will happen only after participation in the public sphere begins. Children who have no opportunity to engage in the state will rely on their parents, and Okin's fear is that many parents will fail in this regard. There is no perfect solution to this problem. A girl raised in a house where women are taught to be silent on political matters will have a disadvantage in learning fairness. Instances like this, however, are why Okin thought that public reason, which limited public discourse to purely political conceptions, was too weak and gave no ability to criticize other families and cultures when change is perhaps necessary.

Taylor can help Rawls here too because he does not adhere to the strong divide between the political and public spheres, and does not try to create a purely political conception of justice. Putting aside what kind of moral psychological development Okin would want the state to promote, Taylor's account of the overlapping consensus, separate from Rawls's idea of public reason, at least gives Okin the ability to bring sexist cultural practices into the public debate in a way that is perhaps more productive than strictly making the equality claims which Rawls argues can cover many of the issues raised by Okin. That being said, an uninformed or politically-motivated critique of another culture can do harm to the mutual trust that Taylor's more inclusive view is trying to achieve. An interesting example of this is the niqab debate that occupied much of the political debate 
in the Canadian federal elections in 2015. The conservative party sought to ban the wearing of niqabs by female Muslim immigrants during their citizenship oath. In an article posted by CBC, then Prime Minister of Canada, Stephen Harper, was quoted as calling the wearing of a niqab "anti-women" in the Canadian Parliament. ${ }^{223}$ These comments could be construed as being along the lines of what Okin wanted. There was public debate concerning the stance of Muslim practices that many viewed as problematically unequal. At the same time, Harper did not strictly break away from Rawls's idea of public reason. By keeping his argument somewhat closely tied to the idea of gender equality, he was speaking in a relatively common language. Harper was trying to build a Canadian identity by demanding certain levels of 'Canadianness' from citizens at certain times. The building of this political identity, according to both Rawls and Taylor, should happen through these kinds of debates. The problem, though, was that the debate lacked any respect towards the third goal of secularism. Few attempts were made to hear or understand the viewpoint of Muslim women. The debate was boiled down to strict and literal ideas of neutrality against religious freedom. It became a hollow debate with no true attempt at mutual understanding.

The way we debate about the values that will be at the core of our society does matter, and ultimately Taylor will give us a better response to Okin than Rawls. Exactly what methods the state is required to develop in order to teach the proper kind of moral psychology is beyond the scope of this thesis. What is important is that the values developed need to go beyond Rawls's account. They need to do more than foster a desire 
for fairness and a willingness to enter into reciprocal relationships. Citizens in a democratic state need to learn to care about recognizing the other viewpoints in society. Then, we can have the ability to criticize other groups in society in the public sphere, but to do so with a goal of understanding and cooperation. Rawls believes that it is enough to teach fairness, because from this, cooperation will follow so long as the other groups in society are also willing to seek fairness through everyone doing their share. When Taylor adds fraternity as a key aspect of secularism, I think he shows us that fairness and cooperation will not immediately follow from basic institutions or fair systems of justice. We need to encourage an active desire for trust and understanding. That is how society can have the kind of debates that Okin wants, without devolving into debates that lack substance, or simply into attacks on groups whom we dislike. An ongoing process in terms of continuously building that trust and cooperation is important too, because it allows us to address the viewpoint of immigrants without falling on never-changing ideals. The idea of citizenship in Canada should grow through a mutual exploration of diversity and not only follow pre-existing ideas of identity. This approach does a better job of creating and perpetuating the conditions for a democratic state because it is more true to the ideals espoused by both Rawls and Taylor.

Jocelyn Maclure argues that something akin to Rawls's public reason is actually a useful civic virtue that should be taught and developed in civic education. When thought of in this way, Rawls's idea of public reason is much more tenable. Maclure first criticizes Rawls for essentially reformulating Kant's categorical imperative. ${ }^{224}$ Rawls, after all, wants political debates to be couched in universal terms and to make reference

224. Jocelyn Maclure, "On the Public Use of Practical Reason," Philosophy and Social Criticism 32 , no. 1 (2006): 41. 
to reason alone. He wants political conceptions to be specific in scope, but general in the way that they fit into the various major comprehensive doctrines. Maclure thinks this move to generality is far too problematic because the appropriate level of generality of any given comment can only be assessed after a discussion has taken place. ${ }^{225}$

Furthermore, there will be widespread disagreement on the appropriateness of a comment and how well it fits this criterion set out by Rawls, and so "we must logically question the status of the generalizability requirement as a binding norm of public argumentation."226 However, Maclure points out the potential usefulness in the idea behind striving to argue in terms that your opposition can readily understand. As such, he contends that being able to put things in a general or universal sense is a civic virtue that should be encouraged by the state. ${ }^{227}$ This approach, I argue, gives us the best possible reading of Rawls. As a strict norm of behaviour on the public stage, the ideal of public reason and the corresponding duty of civility are too restrictive to allow the flexibility necessary to make changing compromises among the various democratic principles that inspire us to pursue fair approaches to diversity in the first place. But if Rawls's public reason is seen as a tool to be used to better the mutual trust and understanding of various comprehensive doctrines in society, then it has pragmatic value and avoids claims of being too exclusive because it does not impose any norms.

If Rawls can be seen as simply desiring fairness, then this will not bring him the stability he requires. I agree that an overlapping consensus is necessary in order to have a just foundation for political sovereignty in democratic states, but said overlapping

225. Maclure, "Practical Reason," 48.

226. Ibid.

227. Ibid., 49. 
consensus needs to be built on ideas that go beyond neutrality and strict adherence to institutional guidelines. Public reason offers too many opportunities for disenfranchisement when taken as a strict norm of political action. When it is taken only as a practical virtue that could help our true goal of mutual understanding, then we can see its utility. Taylor presents an account of an overlapping consensus that avoids the critiques affecting Rawls's account. The state must encourage an ideal of mutual understanding in the development of the moral psychology of its citizens, as this best equips those citizens to deal with diversity in a way that successfully complies with the underlying democratic ideals of freedom, equality, and fraternity. Considered in these terms, an overlapping consensus and Rawls's idea of public reason are good aims for society and respect pluralism as an end rather than a fact.

\subsection{Conclusion}

Rawls's overlapping consensus is a useful model for creating moral allegiance to the basic structures in a liberal society. What matters is how the allegiance is achieved and maintained. Consensus that emerges from a modus vivendi and then transforms into true consensus through Rawls's idea of public reason can face several challenges. The idea of public reason puts limits on justifications that can be given in certain areas of society so that pluralism does not lead to deadlock. More importantly, Rawls intended his duty of civility to ensure that political matters of the state, and debates regarding matters of basic justice, remain political. Many of the critiques of Rawls's idea of public reason fail to understand the scope of the background culture, the proviso, or how many ideas can be translated into more neutral terms while still arguing the same point. Critiques that focus 
on Rawls limiting free speech or barring new ideas can be solved from within Rawls's work. The problems that Rawls cannot respond to as easily are those that show instances where translation fails, is redundant, or is insufficient. We have good reason to believe that political alienation can happen when groups feel that their justifications are devalued by a duty to remain neutral. On the other hand, neutrality must exist in some contexts to avoid comprehensive doctrines from dominating each other.

Taylor gives us a better way to approach these difficulties and navigate through them. Rawls and Taylor both conceive of a society where an overlapping consensus helps form the political identity of the state. The difference is that Rawls argues for the necessity of a duty towards public reason in a way that Taylor does not. Following public reason as anything other than practical advice aimed at furthering mutual understanding between people goes too far. The state has a duty to find common justifications, but expanding that any further makes us value neutrality in itself, rather than the values it is meant to foster. The best way to create moral allegiance to the state through an overlapping consensus is to foster a moral psychology that leads people to value understanding. This is best achieved by focusing on the values behind secularism. 


\section{References}

Barnhart, Michael. "An Overlapping Consensus: A Critique of Two Approaches." The Review of Politics 66, no. 2 (2004): 257-283.

Bohman, James, and Henry S. Richardson. "Liberalism, Deliberative Democracy, and 'Reasons that All Can Accept'." The Journal of Political Philosophy 17, no. 3 (2009): 253-274.

Buxton, Nick. "The Law of Mother Earth: Behind Bolivia's Historic Bill." Global Alliance for the Rights of Nature. Accessed July 15, 2016. $\mathrm{http} / /$ therightsofnature.org/bolivia-law-of-mother-earth.

Drydyk, Jay. "Two Concepts of Overlapping Consensus." In Human Rights: India and the West, 76-92. Edited by Ashwani Peetush and Jay Drydyk. New Delhi: Oxford University Press (India), 2015.

Hartley, Christie, and Lori Watson. "Feminism, Religion, and Shared Reasons: A Defense of Exclusive Public Reason." Law and Philosophy 28 (2009): 493-536.

Macdonald, Neil. "The Niqab Debate, Let's Not Forget, is about Individual Rights," $C B C$ News, September 28, 2015. Accessed September 28, 2015.http://www.cbc.ca/news/politics/canada-election-2015-niqab-neilmacdonald-1.3246179.

Maclure, Jocelyn, and Charles Taylor. Secularism and Freedom of Conscience. Cambridge: Harvard University Press, 2011.

Maclure, Jocelyn. “On the Public Use of Practical Reason." Philosophy and Social Criticism 32, no.1 (2006): 37-63.

Okin, Susan Moller. "Political Liberalism, Justice and Gender." Ethics 105, no.1 (1994): 23-43.

Rawls, John. “Justice as Fairness: Political not Metaphysical." Philosophy \& Public Affairs 14, no. 3 (1985): 223-251.

- "The Domain of the Political and Overlapping Consensus." New York University Law Review 64, no. 2 (1989): 233-255.

—. "The Idea of Overlapping Consensus." Oxford Journal of Legal Studies 7, no. 1 (1987): 1-25.

—. "The Idea of Public Reason Revisited." In The Law of Peoples, 129-180. Cambridge: Harvard University Press, 1999. 
Ryan, Phil. "Stout, Rawls, and the Idea of Public Reason." Journal of Religious Ethics 42 , no. 3 (2014): 540-562.

Sikka, Sonia. "On Translating Religious Reasons: Rawls, Habermas, and the Quest for a Neutral Public Sphere.” The Review of Politics 78 (2016): 91-116.

Solum, Lawrence B. “Novel Public Reasons.” Loyola of Los Angeles Law Review 29 (1995-1996): 1459-1485.

Taylor, Charles. "Conditions of an Unforced Consensus on Human Rights." In The East Asian Challenge for Human Rights, 124-144. Edited by Joanne Bauer and Daniel Bell. Cambridge: Cambridge University Press, 1999.

—. "Why We Need a Radical Redefinition of Secularism." In The Power of Religion in the Public Sphere, 34-59. Edited by Eduardo Mendieta and Jonathan VanAntwerpen. New York: Columbia University Press, 2011.

Tomm, Matthew. "Public Reason and the Disempowerment of Aboriginal People in Canada." Canadian Journal of Law and Society 28, no. 3 (2013):293-314.

Waldron, Jeremy. "Religious Contributions in Public Deliberation." San Diego Law Review 30, no. 4 (1993): 817-848. 